\title{
Review
}

\section{Inorganic scintillating materials and scintillation detectors}

\author{
By Takayuki YANAGIDA*1,†
}

(Communicated by Toshimitsu YAMAZAKI, M.J.A.)

\begin{abstract}
Scintillation materials and detectors that are used in many applications, such as medical imaging, security, oil-logging, high energy physics and non-destructive inspection, are reviewed. The fundamental physics understood today is explained, and common scintillators and scintillation detectors are introduced. The properties explained here are light yield, energy nonproportionality, emission wavelength, energy resolution, decay time, effective atomic number and timing resolution. For further understanding, the emission mechanisms of scintillator materials are also introduced. Furthermore, unresolved problems in scintillation phenomenon are considered, and my recent interpretations are discussed. These topics include positive hysteresis, the co-doping of non-luminescent ions, the introduction of an aimed impurity phase, the excitation density effect and the complementary relationship between scintillators and storage phosphors.
\end{abstract}

Keywords: scintillator, scintillation detector, ionizing radiation, TSL, OSL, RPL

\section{Introduction}

Classification and principles of scintillator. Ionizing radiations have been used for many industrial and scientific purposes since their discoveries more than one hundred years ago. Ionizing radiations are invisible to the naked eye, and some of them have a high penetration power against dense matters. In order to use such ionizing radiations, special tools are necessary to detect and visualize. Such tools are often called radiation detectors; there are two types of solid materials that are most commonly used for radiation detectors. One is semiconductors, and the other is luminescent materials known as scintillators and storage phosphors. ${ }^{1)}$ The former absorbs the energy of ionizing radiation and converts to a large number of carriers, while the latter converts it to a large number of photons; such photons are detected by photodetectors. The number of these carriers or photons is proportional to the quantity or energy of the incident ionizing radiation; thus, we can measure any ionizing radiation. From the view point of the detector types, two kinds of detection methodologies, counting-type and integration-type, are known. In the counting-type detectors, because each radiation

\footnotetext{
*1 Nara Institute of Science and Technology, Nara, Japan.

$\dagger$ Correspondence should be addressed: T. Yanagida, Nara Institute of Science and Technology, 8916-5 Takayama, Ikoma, Nara 630-0192, Japan (e-mail: t-yanagida@ms.naist.jp).
}

signal is processed event-by-event, a fast timeresponse is essentially important. In contrast, the integrated-type detectors detect multiple events over typically a few $m s$ so fast time-response is not required. Semiconductors and scintillators can be applied to the both types of detectors, while storage phosphors can be applied only to the integrated type detectors with a very long integration time (e.g., a few weeks to months). These storage phosphors are mainly used for personnel protection dosimetry, and in this paper I call them dosimeter materials. Figure 1 summarizes a classification of radiation detector materials and detector types.

In this paper, I focus on that scintillators and scintillation detectors. Scintillators are one of the luminescent materials that have a function to absorb ionizing radiations and to emit low-energy photons. ${ }^{2}$ ) First, the absorption of ionizing radiation energy by scintillating materials occurs. The interaction processes depend on the species of ionizing radiation and the elements of the scintillators. When high-energy photons, including $\mathrm{X}$ - and $\gamma$-rays, are absorbed by the scintillator, three interaction processes occur, which are called photoelectronic absorption, Compton scattering and pair creation. Photoelectric absorption is generally used to analyze the radiation, and in this process, one primary electron is generated per event. This primary electron can generate many excited secondary electrons via Coulomb scattering, 


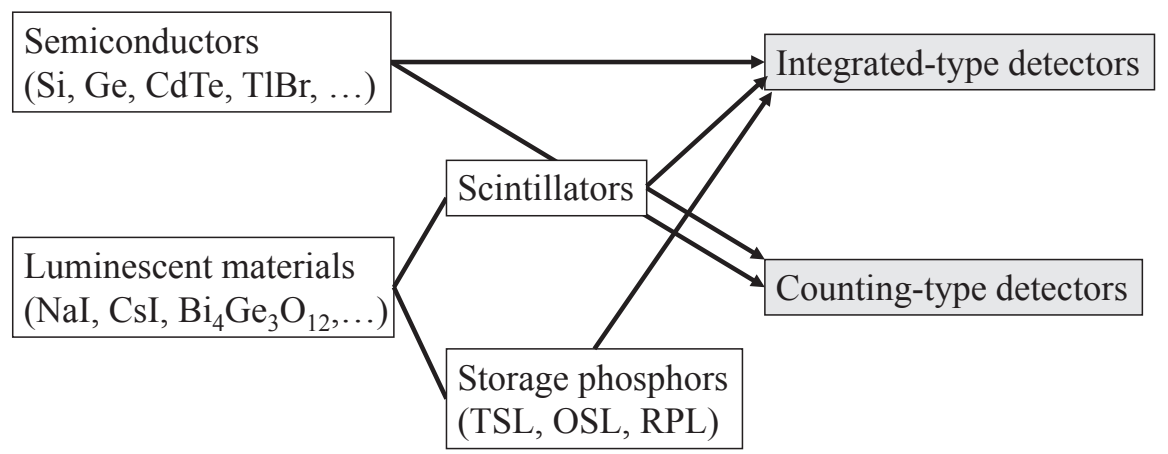

Fig. 1. Classification of solid-state radiation detectors and their detector types.
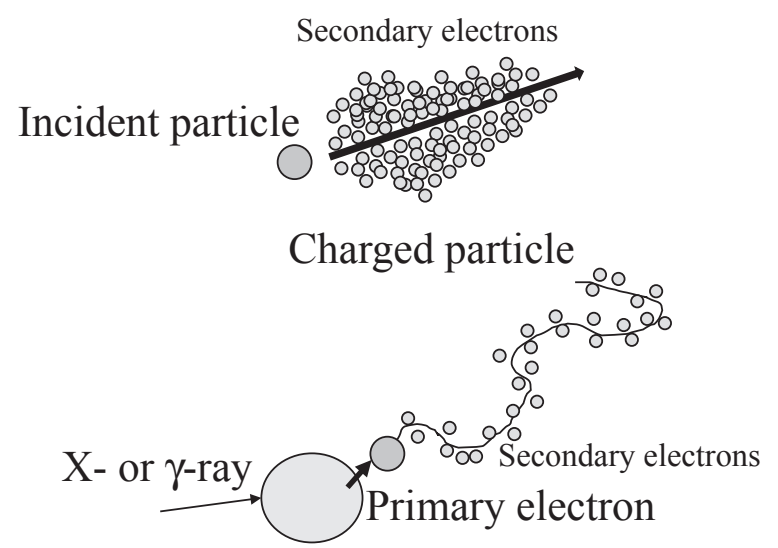

Fig. 2. Schematic drawings of the energy trajectories of charged particle (top) and high-energy photon (bottom) irradiations.

and these secondary electrons dissipate their kinetic energy by interactions with lattice or other free electrons. Finally, these secondary electrons recombine with holes and emit scintillation photons. In the case of charged particles, such as $\alpha$-rays, an energetic charged particle creates many secondary electrons via some interactions such as Coulomb scattering, and these secondary electrons act in the same ways as in the case of $\mathrm{X}$ - and $\gamma$-rays. Although the basic phenomena are similar, a difference can be observed in the excitation density. Figure 2 shows schematic drawings of an ionizing photon and a charged particle interacting with various forms of matter. As schematically shown, the density of excited secondary electrons is high under charged-particle irradiation, and this high excitation density sometimes causes different physical phenomena from the case of photon excitation. Such a difference due to the excitation density is called the linear energy transfer (LET) effect. $^{3)}$

Figure 3 represents a schematic drawing of energy transportation processes of scintillators compared with those of storage phosphors. Generally, the energy-transfer processes in scintillators are understood to consist of three processes. The first is called the conversion process, and at the end of this process, many energetic (excited) secondary electrons are generated. The next is called the transfer process, and in this case, the secondary electrons dissipate their kinetic energy via interactions with the lattice and other electrons. Here, some of the electrons are trapped at localized centers (e.g., lattice defects), and some others can make it to emission centers. The final type is called the luminescence process, in which scintillation photons are emitted. The luminescence processes are mainly two: one is involving the recombination of electrons and holes; the other involve the excitation of luminescent ions by interactions with the energetic secondary electrons. Therefore, in scintillator materials, the secondary electrons are desired to reach the luminescence centers as much as possible. The spatial scale of the dispersion of secondary electrons is around $100 \mathrm{~nm}^{4}$ ) Within a volume of $100 \mathrm{~nm}^{3}$, there are approximately $10^{9}$ atoms, and the number of secondary electrons is around $10^{5}$ per incident radiation quantum of $1 \mathrm{MeV}$. The main luminescence process is a direct recombination of electrons and holes, which is often the case in semiconductor-based (e.g., $\mathrm{ZnO}$ ) scintillators. In contrast, the excitation of luminescent ions is dominant in activator-type scintillators, such as Cedoped materials.

Concerning the processes in dosimeter materials, the first two processes are essentially the same, but the main difference is that most of the generated secondary electrons are captured at trapping centers. These trapped electrons are meta-stable, and can be re-excited by external stimulations, and then emit photons. Thermally stimulated luminescence (TSL) ${ }^{5)}$ and optically-stimulated luminescence (OSL) ${ }^{6)}$ are observed under thermal and optical stimulations, respectively. Taking into account energy conserva- 


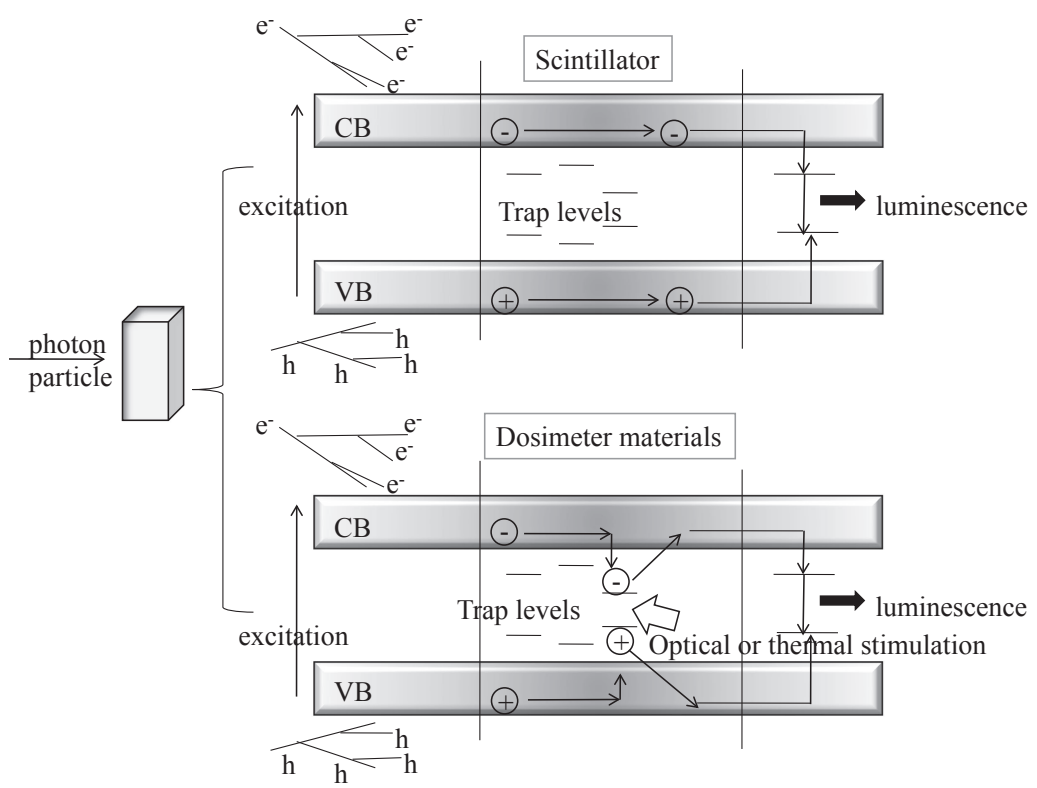

Fig. 3. Energy transport processes of scintillator and dosimeter materials.

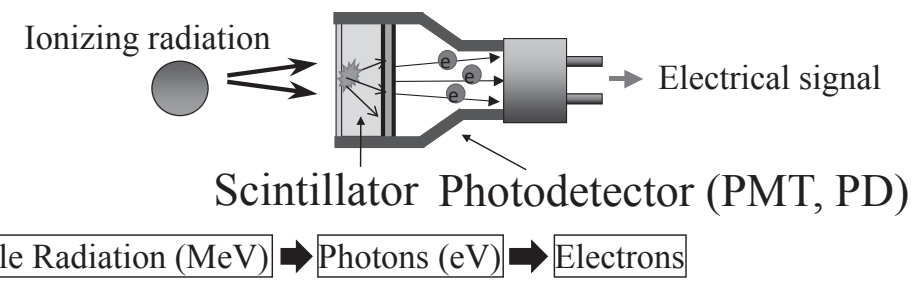

Fig. 4. Sketch of a typical scintillation detector.

tion, the scintillation and storage luminescence should be complementarily related to each other. In other words, bright scintillator materials are dark in storage luminescence, and vice versa. Such a relationship has recently been confirmed experimentally, ${ }^{7), 8)}$ which is one of important approaches to understand the luminescence properties induced by ionizing radiations.

Scintillation detector properties. The scintillation properties required for practical detectors depend on the application. The most common applications of scintillation detectors are medical imaging (PET, X-ray CT, SPECT) ${ }^{9)}$ security, ${ }^{10)}$ oillogging, ${ }^{11)}$ non-destructive studies of cultural objects, ${ }^{12)}$ astro-physics ${ }^{13)}$ and particle-physics. ${ }^{14)}$ The typical construction of a scintillation detector is depicted in Fig. 4. A scintillator is coupled with a photodetector, such as a photomultiplier tube (PMT) and a Si-photodiode (Si-PD) which have a function to convert a scintillation photon to electrons via a photoelectric conversion. The electronic output signals from the photodetector are typically fed into a preamplifier, shaping amplifier, multichannel analyzer, and computer in pulse-height analysis. The required scintillator properties depend on the application, and typical properties to be considered are the light yield, emission wavelength, energy resolution, scintillation decay time, afterglow and high crosssection with the radiation type of interest.

The light yield is one of the most important properties of scintillators as well as other phosphors. Ones with high light yields enable us to detect radiations of low energy (or intensity) with a high signal-to-noise ratio $(\mathrm{S} / \mathrm{N})$. Although there are no solid theories to predict bright scintillators, one phenomenological model is used to explain the observed light yield. ${ }^{15)-18)}$ The model is formulated as $L Y_{\mathrm{sc}}=E /\left(\beta E_{\mathrm{g}}\right) \times S \times Q$, where $L Y_{\mathrm{sc}}$ is the scintillation light yield, $E$ the deposited energy of ionizing radiation, $\beta$ the constant parameter, $E_{\mathrm{g}}$ the band gap energy, $S$ the energy migration efficiency from the host to emission centers and $Q$ the quantum efficiency, which is equal to the photoluminescence (PL) quantum efficiency. In this formula, $\beta E_{\mathrm{g}}$ is the 
energy required to generate a single electron-hole pair, and which is called the $\varepsilon$-value in radiation detector physics. Recently, a convenient empirical formula is used; in that formula, $\beta$ is fixed to 2.5 based on experimental studies of numerous scintillators. ${ }^{18)}$

Sometimes a misunderstanding occurs when distinguishing scintillation and PL. Although there is no concrete or universal definition of scintillation, one important aspect is whether the incident excitation energy can generate multiple carriers or not. In PL, we generally observe the excitation and relaxation of one electron per process. In this definition, an excitation energy of $\sim 0.1 \mathrm{keV}$ should be a rough border between scintillation and PL. Actually, some people call the VUV-excited luminescence (e.g., synchrotron experiments) scintillation, but in most cases these are not scintillations, according to this definition, since the VUV photon energy is on an order of $10-20 \mathrm{eV}$, and it can excite only one electron for most of insulator materials.

In addition to the definition of scintillation (border between scintillation and PL), another argument is sometimes regarded as evaluation methodologies to determine the light yield. Emission spectrum excited by ionizing radiation is called radioluminescence, and some groups use the area of the radioluminescence to evaluate the scintillation light yield. Unfortunately, it is an incorrect methodology in most cases. In the radioluminescence spectrum, the signal intensity depends not only on the scintillation light yield, but also on the stopping power of the material. Simply speaking, the intensity of the radioluminescence is roughly proportional to the product of the scintillation light yield and the stopping power. If we compare two materials with the same absolute light yields, but with different stopping powers, the heavier material will show a higher radioluminescence intensity, although the scintillation light yields are the same. For this reason, except for some special cases, pulse-height spectroscopy must be conducted to determine the scintillation light yield. Special cases are, for example, to compare those materials with practically close stopping power (chemical composition). Actually, the light-yield values of common scintillators are evaluated by pulse height analysis, and with the present technologies available to determine the scintillation light yield of slow materials that have a scintillation decay time longer than $100 \mu \mathrm{s}$ is difficult.

Another important aspect is energy nonproportionality of the scintillation light yield. In scintillators, the number of emitted photons per unit energy

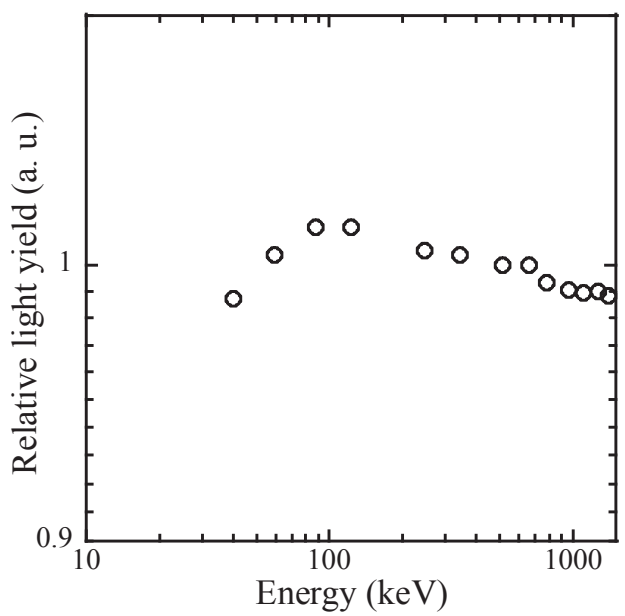

Fig. 5. Relative light yield of an Eu-doped $\mathrm{SrI}_{2}$ crystal scintillator plotted against $\gamma$-ray energy. The light yield is defined as 1 at $662 \mathrm{keV}$.

differs according to the excitation energy, and such a relation is called the energy nonproportional response of a scintillator, or simply nonproportionality. Figure 5 demonstrates the nonproportionality of Eu-doped $\mathrm{SrI}_{2} \cdot{ }^{19)}$ In this graph, ratios of the number of scintillation photons to the corresponding incident energy is plotted relative to that measured with $662 \mathrm{keV} \gamma$-ray excitation, which is defined as 1 . Although the vertical axis of the nonproportionality graph does not represent any physical value, it can be understood as being something like (not exactly) an energy conversion efficiency from ionizing radiation to scintillation photons. As shown in Fig. 5, Eudoped $\mathrm{SrI}_{2}$ has a peak at around $100 \mathrm{keV}$, and it is well-known that almost all scintillators have similar features. To the best of my knowledge, there is no confirmed theories to explain this phenomenon, but for practical applications we must select a scintillator suited for the target energy. Otherwise, energy corrections of the obtained data become very difficult.

The emission wavelength must match with the sensitive wavelength of photodetectors. Typical photodetectors are PMT and Si-PD. The former typically has a spectral sensitivity from 300 to $600 \mathrm{~nm}$, while the latter is sensitive to photons with wavelengths longer than $500 \mathrm{~nm}$. Figure 6 represents the quantum efficiencies of PMT, Si-PD and some gas-type photodetectors for vacuum ultra-violet (VUV) detections. Although the quantum efficiency of PMT is lower than PD, PMT allows for a much higher multiplication gain of up to $10^{6}$. TMAE (tetrakis dimethylamine ethylene) and TEA (tetra ethyl amine) are gases, which are used in gas-PMT. ${ }^{20)}$ 


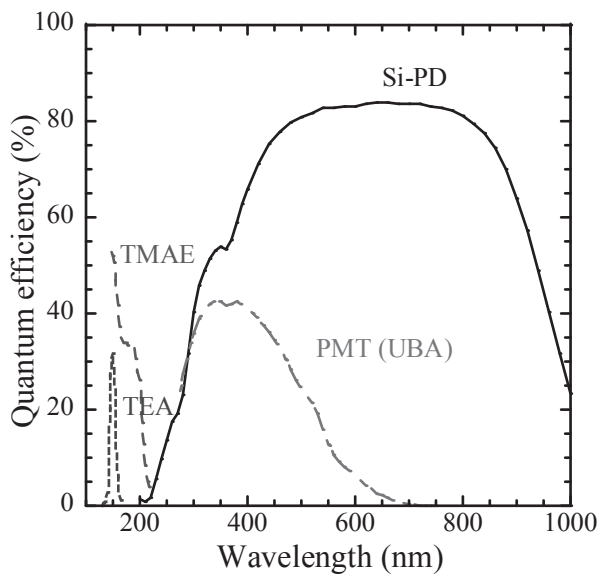

Fig. 6. Quantum efficiency (\%) plotted against the wavelength $(\mathrm{nm})$. The data is taken from. ${ }^{21)}$

VUV photodetectors are currently undergoing the R\&D phase, and especially the stability and reproducibility are problems. The signal intensity of scintillation detectors depends on the product of the scintillation light yield and the quantum efficiency of the photodetectors; thus, the common practical scintillators are ultraviolet (UV) and visible (VIS) photon-emitting materials since the PMT and $\mathrm{PD}$ devices are sensitive from UV to near-infrared (NIR) wavelengths.

Energy resolution $(\Delta E)$ is defined as $\Delta E=$ FWHM/Ch ${ }_{\text {peak }}$, where FWHM and $\mathrm{Ch}_{\text {peak }}$ represent the full-width at half-maximum (FWHM) and the peak channel of the photoabsorption peak in pulseheight spectrum, respectively. In a first-order approximation, the energy resolution depends on the Poisson statistics of the electrons from the photodetectors, which is essentially proportional to the light yield. If the energy resolution is sufficiently high, we can distinguish the radiation species with very close emission energies in practical applications as scintillation counters. For example, the $\gamma$-ray energies of ${ }^{134} \mathrm{Cs}$ and ${ }^{137} \mathrm{Cs}$ are 604 and $662 \mathrm{keV}$, respectively, and a sufficiently high energy resolution is required to distinguish these two peaks in pulse-height spectrum. Although there are no solid explanations available, empirical observations show that the energy resolution is $3-4 \%$ at $662 \mathrm{keV}$, which is the highest of all; it does not seem to improve even if the scintillation light yield increases. In the case of Pr-doped $\mathrm{Lu}_{3} \mathrm{Al}_{5} \mathrm{O}_{12}$, it has a light yield of $20,000 \mathrm{ph} / \mathrm{MeV}$ and the energy resolution of $3-4 \%$ at $662 \mathrm{keV} .^{22)}$ The energy resolutions of Ce-doped $\mathrm{LaBr}_{3}{ }^{23)}$ which has a light yield of $60,000 \mathrm{ph} / \mathrm{MeV}$ and Eu-doped $\mathrm{SrI}_{2},{ }^{19)}$ which shows $80,000 \mathrm{ph} / \mathrm{MeV}$, are also $3-4 \%$ at $662 \mathrm{keV}$. Therefore, if the scintillation light yield is sufficiently high, the energy resolution is no longer governed by Poisson statistics. The difference between Poisson statistics and the actual energy resolution is called the Fano factor. In order to understand the physics governing the energy resolution, investigations on the Fano factor must be made. Before the 21st century, such a discussion was not considered, since the energy resolution was at most $7-10 \%$ at $662 \mathrm{keV}$, and the recent development of novel high-energy resolution scintillators has opened up this new discussion. Up to now, the highest energy resolution has been achieved by co-doped $\mathrm{LaBr}_{3}$; the resolution was around $2 \%$ at $662 \mathrm{keV}{ }^{24)}$ If the energy resolution becomes $1 \%$ at $662 \mathrm{keV}$, it offers a comparable resolution of CdTebased semiconductor detectors, and many new applications of scintillation detectors would be established.

The scintillation decay time is one of the important properties for scintillation detectors, and is directly related to the timing resolution of radiation detectors. The decay time is fundamentally governed by the speed of transfer of free electrons and holes from an ionization track to the emission center and the lifetime of the luminescence state of the activator. In PL, the luminescence decay time can be analytically deduced as being $\Gamma=$ $\frac{1}{\tau} \propto \frac{n}{\lambda^{3}}\left(\frac{n^{2}+2}{3}\right)^{2} \sum_{f}|\langle f|\mu| i\rangle|^{2}$, where $\Gamma, \tau, n$ and $\lambda$ represent the decay rate of an excited state, decay time, refractive index and emission wavelength, respectively. The matrix element connecting the initial state, $|i\rangle$, with the final state, $\langle f|$, via the dipole operator, $\mu$, will only be of appreciable size for transitions between states of different parity. ${ }^{25)}$ Although other processes of energy migration from the host lattice to emission centers can be involved, the scintillation decay time is approximately proportional to $\lambda^{3}$. Previously, the relation between the scintillation decay time and refractive index was wellstudied experimentally. ${ }^{26)}$ Following this study, we investigated the relation between the scintillation decay time and the emission wavelength experimentally; the decay time was proportional to $\sim \lambda^{2.2}{ }^{27}$ ) Figure 7 represents the relationship between the decay time, $\tau$, and the emission wavelength, $\lambda$, in $\mathrm{PL}$ and the scintillation. In this work, it was proved that the relationship in PL decay and the emission wavelength could also be applied to the scintillation phenomenon.

In the $\mathrm{R} \& \mathrm{D}$ of scintillator materials, the chemical formula must be considered. For example, if the aim is to detect high-energy photons, such as Xand $\gamma$-rays, dense materials composed of high $Z_{\text {eff }}$ 


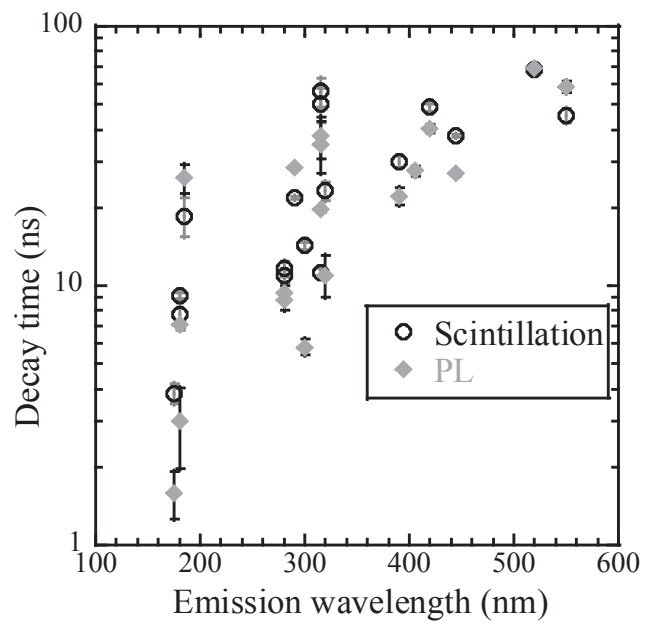

Fig. 7. Relationship between the emission wavelength (nm) and the decay time (ns) in PL and scintillation.

(effective atomic number) are preferred. Although there are no concrete expressions, the effective atomic number for photoelectric absorption can be expressed as $Z_{\text {eff }}=\left(\Sigma w_{\mathrm{i}} Z_{\mathrm{i}}^{4}\right)^{1 / 4}$ where $w_{\mathrm{i}}$ and $Z_{\mathrm{i}}$ are the fraction of the total mass associated with the $i$-th element and the atomic number of the $i$-th element, respectively. For dosimeter applications, sometimes the power of $Z_{\text {i }}$ may take 2.94. Therefore, empirically, powers of 3-4 are used; the value depends on the application. In addition, if the purpose is to detect neutrons, materials composed of light elements are used, and ${ }^{6} \mathrm{Li}$ or ${ }^{10} \mathrm{~B}$ should be included in the matrix, since these elements have a high cross-section to thermal neutrons. In the case of charged-particle detectors, materials with intermediate $Z_{\text {eff }}$ are preferred because there are many background photons and neutrons in the measurement environment of charged particles.

The timing resolution is similar, but different, from the scintillation decay time. The timing resolution is important for high counting-rate applications, such as PET. On the side of scintillator materials, the timing resolution mainly depends on the number of scintillation photons of the fast component. This fast component can be effectively detected and converted to an electrical signal as long as the spectrum of incident photons matches the spectral sensitivity of the detector. In addition, the response time of the photodetector also affects the timing resolution. Typically, a scintillator has a multi-component decay time, and the presence of a slow component degrades the timing resolution. It must be noted that the timing resolution is not a physical property of scintillators, but a detector property determined by the combination of a scintillator, photodetector and readout electronics; thus, it is impossible to control the timing resolution only by tuning the scintillator properties. This is a different point of scintillation properties from others mentioned above.

\section{Recent R\&D progress of scintillators}

Brief history. The discovery of ionizing radiation was in the late 19 th century; at that time, pioneers such as Roentgen and Edison discovered that $\mathrm{Ba}\left[\mathrm{Pt}(\mathrm{CN})_{4}\right]$ emitted visible photons under the irradiation of X-rays. ${ }^{28)}$ Obviously, these visible photons were scintillation photons. By a several decades after the discovery of X-rays, other species of ionizing radiation had been discovered continuously, and together with the invention of photodetectors, many kinds of scintillators had been developed. At the beginning of the R\&D history of the scintillator, alkali halide materials (e.g., $\mathrm{NaI}^{29)}$ and $\mathrm{CsI}^{30)}$ ) and natural phosphors (e.g., $\mathrm{CaF}_{2}{ }^{31)}$ and $\mathrm{CdWO}_{4}{ }^{32)}$ ) were targeted to be investigated. As known, $\mathrm{CaF}_{2}$ and $\mathrm{CdWO}_{4}$ are called fluorite and scheelite in mineralogy, respectively. In the era from the 1940s to $1960 \mathrm{~s}$, some of the scintillators well-known today were developed, such as Tl-doped NaI ${ }^{29)}$ Tl-doped $\mathrm{CsI}^{30}$ ) and Eu-doped $\mathrm{CaF}_{2} \cdot{ }^{31}$ ) After the $1980 \mathrm{~s}$, some new materials that did not exist in the natural world were developed, and some standard materials today, such as $\mathrm{Bi}_{4} \mathrm{Ge}_{3} \mathrm{O}_{12}$ (BGO), ${ }^{33)}$ were found. Compared with $\mathrm{NaI}$, CsI and $\mathrm{CaF}_{2}$, the effective atomic number of BGO is very high, so BGO was used in the early types of PET. Following the invention of BGO in this era, notable R\&D was performed, which was Ce-doping in insulating host materials, and the Cedoping became a standard approach to develop new scintillators until now. Ce-doped $\left.\mathrm{Lu}_{2} \mathrm{SiO}_{5}(\mathrm{LSO})^{34}\right)$ and its Y-admixture $\mathrm{LYSO}^{35)}$ are now standard materials. Actually, the most recent types of PET are equipped with Ce-doped LYSO instead of BGO. Recently, Ce-doped $\mathrm{Gd}_{3}(\mathrm{Al}, \mathrm{Ga})_{5} \mathrm{O}_{12}(\mathrm{GAGG})^{36)}$ was developed by the author and collaborators, and is now widely used with Si-based photodetectors. Except for Ce-doped garnet scintillators, the emission wavelength of commercial scintillators is 300$400 \mathrm{~nm}$; these Ce-doped garnet scintillators are the only type applicable for PD-based radiation detectors. Figure 8 summarizes the R\&D history of common scintillators. Among these scintillators, the author contributed to develop GYAG, ${ }^{37)}$ GAGG, ${ }^{36)}$ Eu:SrI ${ }_{2}^{38)}$ and $\mathrm{LiCaAlF}_{6} \cdot{ }^{39), 40)}$ The recent trend is to develop host materials of complex compositions, and the combination of an insulator host and a doped 


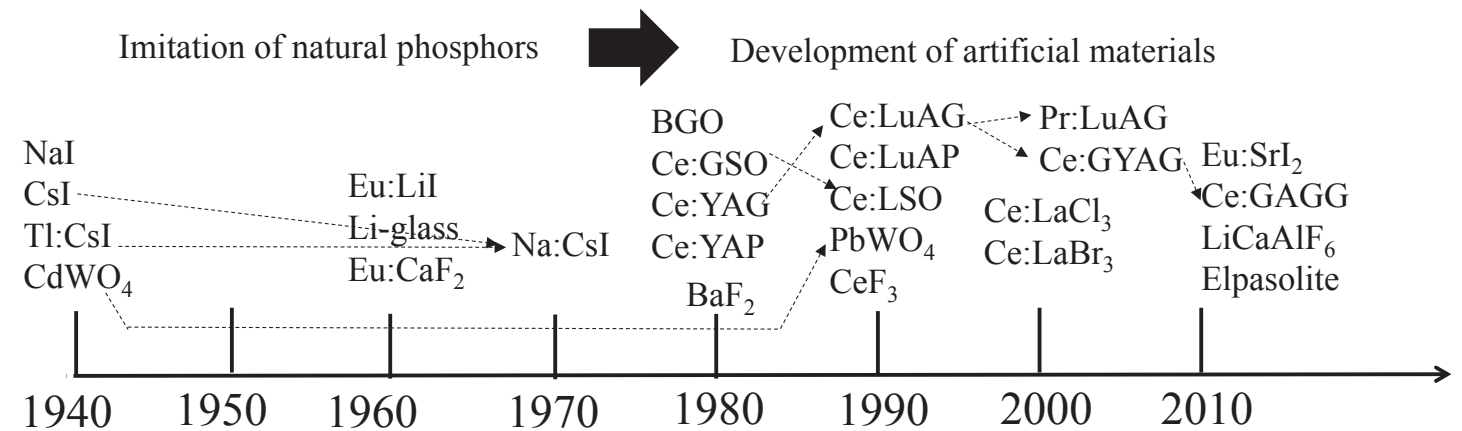

Fig. 8. R\&D History of common scintillators. Arrows indicate modifications of materials.

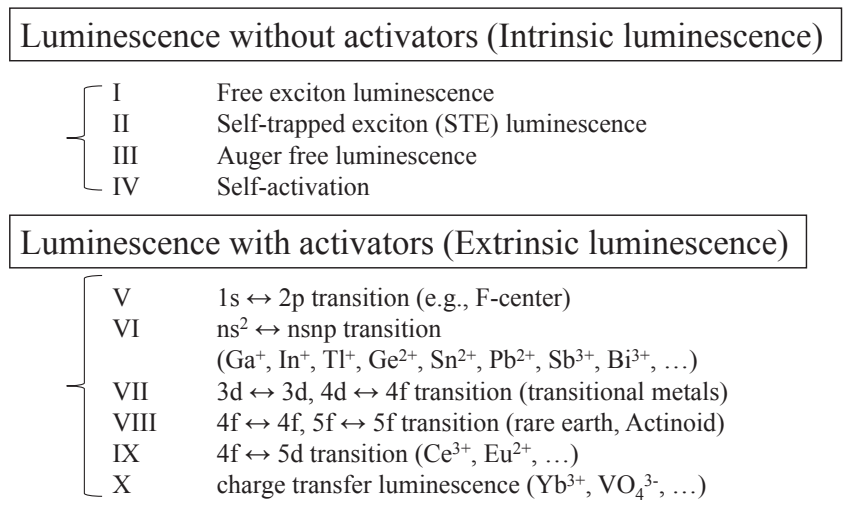

Fig. 9. Classification of the emission mechanisms of scintillators.

emission center has become a standard approach to achieve higher performance.

Emission mechanisms. In the history of scintillators and scintillation detectors, many kinds of scintillators have been developed. The emission mechanisms are sometimes considered so as to overview the scintillator materials, since important scintillation properties (e.g., emission wavelength and decay time) strongly depend on the emission mechanisms. Also these properties greatly affect scintillation detector properties. Figure 9 shows a classification of the emission mechanisms involved in scintillators. It should be noted that there are no confirmed classification in this field of study, and this figure is a classifications I use.

There are two kinds of luminescence in scintillators: intrinsic and extrinsic. The intrinsic luminescence represents free-exciton luminescence, selftrapped exciton (STE) luminescence, Auger free luminescence and self-activation luminescence. The free exciton luminescence is observed in wide bandgap semiconductor materials having direct transitions; common examples are $\mathrm{ZnO}^{41-43)}$ and $\mathrm{GaN} .{ }^{44)}$ Scintillation due to free exciton is characterized by fast scintillation decay with a sharp emission peak in the spectrum. Recently, I found a newly developed semiconductor material, $\mathrm{Ga}_{2} \mathrm{O}_{3}$, which also shows fast and very intense scintillation upon $\gamma$-ray irradiation, ${ }^{45)}$ although it is under discussion whether the emission is like that of a direct transition semiconductor or not. Among the semiconductor scintillators developed so far, $\mathrm{Ga}_{2} \mathrm{O}_{3}$ has been confirmed to show the highest scintillation light yield, and we continue to study this scintillator. ${ }^{46), 47)}$

STE can be observed in wide-band-gap insulator materials, such as undoped alkali halides. The most common materials are $\mathrm{BaF}_{2},{ }^{48)} \mathrm{SrF}_{2},{ }^{49)} \mathrm{CaF}_{2}{ }^{50)}$ and their mixed compounds. ${ }^{51), 52)}$ Common properties of STE are a broad emission peak in the emission spectrum, a large Stokes shift, a relatively high light yield in scintillation, a relatively fast decay time from several hundred ns to few $\mu$ s and a large temperature dependence of the scintillation light yield.

Auger free luminescence is observed in some materials having a special condition, which is a larger band gap energy than the energy between the core and the valence bands. ${ }^{53)}$ Auger free luminescence undergoes a very fast luminescence decay with a 
short emission wavelength; the common materials are $\mathrm{BaF}_{2},{ }^{48)} \mathrm{BaMgF}_{4},{ }^{54)} \mathrm{CsF}^{55)}$ and $\mathrm{Cs}_{2} \mathrm{ZnCl}_{4} \cdot{ }^{56)} \mathrm{As}$ in these examples, Auger free luminescence is observed in halide materials, and a search for other compounds (oxides and nitrides) is an interesting research topic. Conventionally, it was considered that they have no temperature dependence concerning the scintillation light yield;57) but we recently revealed that Auger free luminescence materials also shows a temperature dependence. ${ }^{58)}$

Self-activation type scintillators are composed by the host, and in this context this type can be classified as belonging to the intrinsic luminescence type materials. The difference from other intrinsic-type materials is that the host material consists of luminescent ions as a main constitutional element. Common scintillators of this type are $\mathrm{BGO},{ }^{33)} \mathrm{CeF}_{3}{ }^{59}$ ) and $\mathrm{CeBr}_{3}{ }^{60)}$ Scintillations from BGO are caused by $\mathrm{ns}^{2}$ transitions of $\mathrm{Bi}^{3+}$, and those of the latter two materials are due to the $5 \mathrm{~d}-4 \mathrm{f}$ transitions of $\mathrm{Ce}^{3+}$. The emission properties are governed by the luminescent ions of the host, and interestingly, this class of materials do not suffer from concentration quenching.

We now consider luminescence with activators. Materials containing F-centers show scintillation. The F-center is a defect-based luminescence center, and one electron is captured at an anion vacancy. Common materials with an F-center are simple oxide materials, such as $\mathrm{MgO}^{61)}$ and $\mathrm{Al}_{2} \mathrm{O}_{3} \cdot{ }^{62)}$ In addition to F-centers, there are some other defect-based luminescence centers known as, for example, $\mathrm{F}^{+}$and $\mathrm{F}^{-}$-centers. Although defects are not exactly activators, defect-based luminescence is sometimes categorized as being extrinsic emission.

Luminescence due to the $\mathrm{ns}^{2} \leftrightarrow$ nsnp transition is one of the common electron transitions involved in many scintillators, such as Tl-doped NaI, Tl-doped CsI and BGO. The spectral feature of the ns ${ }^{2} \leftrightarrow$ nsnp transition is characterized by broad emission band, and the emission wavelength is from near UV to VIS. Because of the decay time is from several hundred ns to several $\mu \mathrm{s}$, it is acceptable for pulse-height-based radiation detectors. In this type of luminescence, in addition to $\mathrm{Tl}^{+}$and $\mathrm{Bi}^{3+}, \mathrm{In}^{+63)}$ and $\mathrm{Sn}^{2+64)}$ were discovered to show promising scintillation properties in recent years.

In scintillators, transitional metal ions are sometimes included to obtain a high luminescent efficiency when a fast decay time is not required. The spectrum of $3 \mathrm{~d}-3 \mathrm{~d}$ and $4 \mathrm{~d}-4 \mathrm{~d}(\mathrm{~d}-\mathrm{d})$ transitions has a broad luminescence feature, and the decay time is typically on the ms order. Among the transitional metal elements, $\mathrm{Mn}^{2+65)}$ and $\mathrm{Cr}^{3+66)}$ are sometimes selected for scintillation detectors due to a good spectral matching with Si-PD.

Transitions of the $4 \mathrm{f}-4 \mathrm{f}$ and $5 \mathrm{f}-5 \mathrm{f}$ levels are called $\mathrm{f}-\mathrm{f}$ transitions, and some scintillators use the $4 \mathrm{f}-4 \mathrm{f}$ transitions of rare-earth elements. The most common scintillator based on the $4 \mathrm{f}-4 \mathrm{f}$ transition is $\mathrm{Pr}^{3+}$ doped $\mathrm{Gd}_{2} \mathrm{O}_{2} \mathrm{~S}$ (GOS), ${ }^{67)}$ which is equipped in medical X-ray CTs. The Pr-doped GOS shows a very high scintillation intensity with a decay time of medium range (several $\mu \mathrm{s})$. The luminescence due to the $4 \mathrm{f}-4 \mathrm{f}$ transitions of $\mathrm{Pr}^{3+}$ appear in yellow-green, which is well-matched with the spectral sensitivity of Si-PD. For practical uses, $\mathrm{Ce}^{3+}$ is co-doped to suppress the afterglow level. Recently, $\mathrm{Eu}^{3+}$-doped $(\mathrm{Lu}, \mathrm{Gd})_{2} \mathrm{O}_{3}{ }^{68)}$ has attracted much attention for $\mathrm{X}$ ray $\mathrm{CT}$. The emission intensity is higher than other materials, and the emission wavelength is in red, which is suited to Si-PD readout. In addition to these materials, we have investigated doping with other rare-earth ions in order to develop near infrared emitting scintillators. For this purpose, $\mathrm{Nd}^{3+69)}$ has been selected as the emission center.

Emission due to 5d-4f transitions of trivalent and divalent rare-earth ions are very important for scintillation detectors because they show intense and fast emissions by the spin- and parity-allowed transitions. The most common emission center is $\mathrm{Ce}^{3+}$, and examples of commercial scintillators are Ce-doped LSO, ${ }^{34)}$ LYSO, ${ }^{35)}$ GAGG, ${ }^{36)}$ YAG $^{70}$ ) YAP ${ }^{71)} \mathrm{LaCl}_{3},{ }^{72)} \mathrm{LaBr}_{3}{ }^{73)}$ and $\mathrm{Cs}_{2} \mathrm{LiYCl}_{6} \cdot{ }^{74}$ Except for garnet materials, including GAGG, most scintillators have emission wavelengths of 300-400 nm with 30-60 ns decay times; these properties are suitable for PMT readout. In addition to $\mathrm{Ce}^{3+}, \mathrm{Pr}^{3+}$ can also show luminescence due to the $5 \mathrm{~d}-4 \mathrm{f}$ transition in some host materials. The appearance of the $5 \mathrm{~d}-4 \mathrm{f}$ transition depends on the relative positions between the lowest $5 \mathrm{~d}$ and ${ }^{1} \mathrm{~S}_{0}$ levels. Common Pr-doped scintillators are Pr-doped $\mathrm{LuAG}^{75)}$ and YAP, ${ }^{76)}$ which show light yields of $10,000-20,000 \mathrm{ph} / \mathrm{MeV}$ with a 20 ns decay time. Compared with Ce-doped scintillators, the emission of Pr-doped materials appears in a shorter wavelength range. Some other trivalent rare-earth ions show $5 \mathrm{~d}-4 \mathrm{f}$ transitions only in hosts having a wide-band gap energy, and the emission wavelength is in VUV. A common example is $\mathrm{Nd}$-doped $\mathrm{LaF}_{3}$, which has an emission wavelength at $175 \mathrm{~nm}$ with a few-ns decay time ${ }^{77)}$ due to the $5 \mathrm{~d}-4 \mathrm{f}$ transition of $\mathrm{Nd}^{3+}$. Divalent Eu can also show a very high scintillation light yield with typically a $1 \mu \mathrm{s}$ decay time; example scintillators are $\mathrm{Eu}^{2+}$-doped 


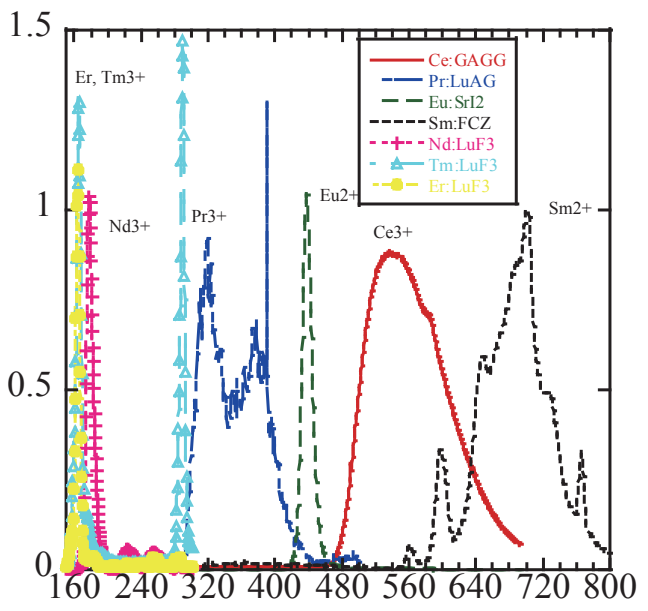

Wavelength (nm)

Fig. 10. Scintillation spectra of $\mathrm{Nd}^{3+}-\mathrm{Er}^{3+}-$ and $\mathrm{Tm}^{3+}$-doped $\mathrm{LuF}_{3},{ }^{82}$ Ce-doped GAGG, ${ }^{36)}$ Pr-doped LuAG, ${ }^{75)}$ Eu-doped $\mathrm{SrI}_{2}{ }^{38)}$ and Sm-doped FCZ glass-ceramics. ${ }^{79)}$

$\mathrm{SrI}_{2},{ }^{38)} \mathrm{CaF}_{2},{ }^{31)} \mathrm{LiI}^{78)}$ and $\mathrm{LiCaAlF}_{6}{ }^{40)}$ Recently, luminescence due to the 5d-4f transitions of $\mathrm{Sm}^{2+}$ ions was also reported, ${ }^{79)-81)}$ and investigations are in progress. $\mathrm{Sm}^{2+}$ shows emission in the near-infrared range, and has attracted much attention for use with Si-PD type photodetectors. Recent trends in the development of scintillators involve those rareearth-doped materials possessing $5 \mathrm{~d}-4 \mathrm{f}$ transitions; Fig. 10 shows typical scintillation spectra of such scintillators. $\mathrm{Nd}^{3+}, \mathrm{Er}^{3+}$ and $\mathrm{Tm}^{3+}$ show emissions in the VUV range, $\mathrm{Pr}^{3+}$ in the near UV range, $\mathrm{Ce}^{3+}$ and $\mathrm{Eu}^{2+}$ in the VIS range, and $\mathrm{Sm}^{2+}$ in the near-infrared range. It should be noticed that the emission wavelength by $5 \mathrm{~d}-4 \mathrm{f}$ transitions strongly depends on the crystal field, which is specific to each host lattice; the presented data are only examples.

Charged transfer luminescence can be observed in some atomic groups, such as $\mathrm{Yb}^{3+}$-doped materials as well as $\mathrm{VO}_{4}{ }^{3-}$ and $\mathrm{WO}_{4}{ }^{2-}$. Examples of the former type is $\mathrm{Yb}$-doped $\mathrm{Lu}_{2} \mathrm{O}_{3}{ }^{83}$ and $\mathrm{Yb}$-doped garnet materials, ${ }^{84)}$ while examples of the latter are $\mathrm{YVO}_{4}{ }^{85}$ ) and $\mathrm{CaWO}_{4}{ }^{86)}$

On one hand, the charge-transfer luminescence of $\mathrm{Yb}^{3+}$ is known to have a very fast decay with a low light yield due to thermal quenching at room temperature. On the other hand, the charge transfer luminescence of the $\mathrm{VO}_{4}{ }^{3-}$ and $\mathrm{WO}_{4}{ }^{2-}$ atomic groups are slow (typically several $\mu \mathrm{s}$ ), but they have a large light yield of $10,000-20,000 \mathrm{ph} / \mathrm{MeV}$. Among the materials with charge-transfer luminescence, $\mathrm{CdWO}_{4}$ has been used with $\mathrm{Si}-\mathrm{PD}^{87}$ ) for X-ray detectors for security applications.
Recent R\&D of scintillators for X- and $\gamma$-ray detectors. Among many applications of ionizing radiation, high-energy photons, such as $\mathrm{X}$ - and $\gamma$ rays, are the most commonly utilized, since they can be generated relatively easier than other species of ionizing radiation. Especially, these high-energy photons have a high penetration power to matters including the human body; thus, a non-destructive study of inner objects is a main application. In X-and $\gamma$-ray detectors, scintillators are required to have a

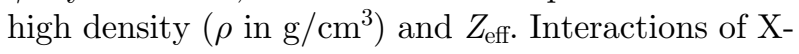
and $\gamma$-rays with matter mainly include three types: photoelectric absorption (sometimes called photoabsorption), Compton scattering and pair creation, as well as their interaction probabilities depend on $\sim \rho Z_{\text {eff }}^{4}, \rho Z_{\text {eff }}$ and $\rho Z_{\text {eff }}^{2}$, respectively. The events of photoelectric absorption are often utilized in practical detectors (pulse-counting type), since it represents information concerning the incident X- or $\gamma$-ray energy. Recently, Compton scattering is also used to determine the position of $\mathrm{X}$ - or $\gamma$-ray sources (Compton camera detector); this concept works only in the pulse-counting mode.

Figure 11 shows the typical detector configurations of X- and $\gamma$-ray detectors. For X-ray detectors, scintillators are typically coupled with Si-PDs, and each pixel is separated by $\mathrm{Pb}$ or $\mathrm{W}$ collimator to maximize the imaging resolution. Because most Xray detectors are used for medical imaging and security inspection systems, a position sensitivity is of primal requirement. To observe a clear image, the detection of scattered X-rays should be avoided as much as possible, and collimators are typically used for this purpose. In conventional detectors, the collimators on the detection plane are a dead area, but recently $R \& D$ has attempted to use them as an active area. One of the methodologies uses a socalled functional collimator. ${ }^{88)}$ In this concept, the collimator material acts as both a collimator and a scintillator, and shows scintillation. In order to distinguish the signals detected in the primary scintillators and collimator parts, a pulse-shape discrimination technique can be applied.

In pulse-counting-type detectors, the most conventional detectors consist of a large scintillator coupled with PMT, and are mainly used for $\gamma$-rays. Although there are no confirmed definitions to separate between $\mathrm{X}$-rays and $\gamma$-rays, a typical understanding is that $\gamma$-rays are high-energy photons emitted via transitions between energy levels in radioisotopes (radioactive decay), while $\mathrm{X}$-rays are generated by interactions with the accelerated 


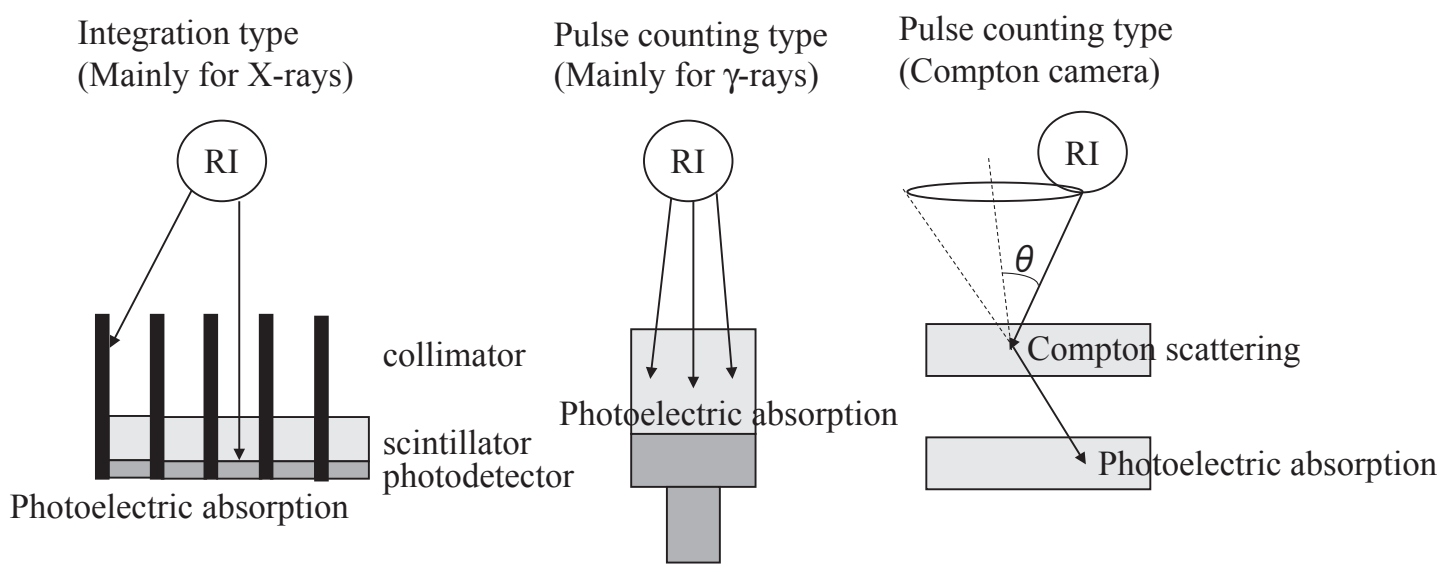

Fig. 11. Typical detector configurations of the integration and pulse counting type.

electrons and anode materials or by bending trajectories of accelerated particles. Thus, the $\gamma$-ray spectrum appears to be a sharp line structure due to the well-defined energy levels while X-rays consist of a broad spectrum structure with the endpoint of energy defined by the highest energy of accelerated electrons. Radiation detectors consisting of one scintillator with one PMT are probably the simplest configuration, and are used for survey meters and well-logging detectors. In most particle detectors, such as $\alpha$-ray and neutron detectors, the same configuration is used on a pulse-counting mode. Unlike the case of X-ray detectors, most $\gamma$-ray detectors do not use collimators, since it is difficult to collimate high-energy photons, and also the use of most $\gamma$-ray detectors are not to obtain images, but to count the number of $\gamma$-rays in the pulse-height spectrum. Among detectors for nuclear imaging, SPECT uses collimators, since the target $\gamma$-ray energies are not high, and PET use the coincidence technique for $511 \mathrm{keV}$ annihilation $\gamma$-rays.

For $\gamma$-ray detectors, a Compton camera has recently been developed and used in practical applications. The root of the Compton camera was high-energy astrophysics in the $1990 \mathrm{~s},{ }^{89}$ ) since the Compton scattering was a dominant event in $\mathrm{MeV}$ $\gamma$-rays, which were a main target of high-energy astrophysics. Generally, a Compton camera uses two detection parts. One is a scatterer where Compton scattering takes place, and the other is an absorber where photoelectric absorption is utilized. In these two detector parts, radiation energies are deposited, and the sum of these energies equals to the incident $\gamma$ ray energy. From the formula of Compton scattering, if we know the incident radiation energy (specie), we can find the angle of the Compton scattering $(\theta$, in

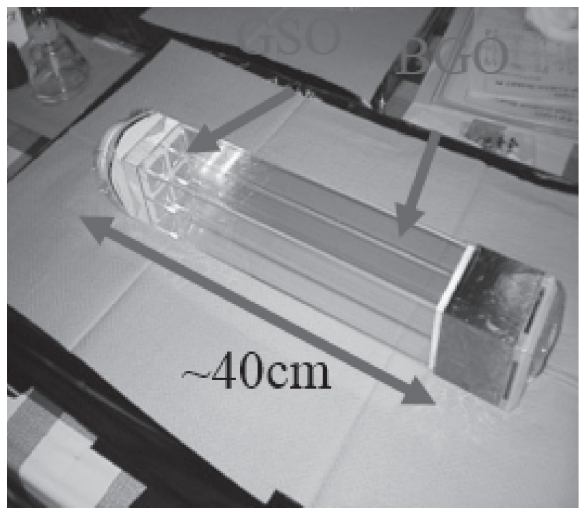

Fig. 12. Picture of the $\gamma$-ray detector onboard the Suzaku satellite.

Fig. 11), and we know that the radiation source is somewhere on the circle drawn in Fig. 11 (right). By superposing circles in many events, the position of the radiation source can be determined eventually. In the Compton camera, not only scintillators, but also semiconductor detectors, are used. Figure 12 shows a $\gamma$-ray detector that I constructed. It consisted of Ce-doped $\mathrm{GSO}^{90)}$ and BGO scintillators. The scintillation decay times of GSO $(\sim 60 \mathrm{~ns})$ and BGO ( $\sim 300 \mathrm{~ns})$ were different, and the pulse-shape discrimination was used to distinguish. As shown in the figure, the size of the detector was several tens of $\mathrm{cm}$ in length to absorb $\gamma$-rays efficiently; 16 detector units were arrayed. This $\gamma$-ray detector was actually onboard the Suzaku satellite, ${ }^{91)}$ and observed highenergy $\gamma$-rays from stars and galaxies in the universe.

For such $\mathrm{X}$ - and $\gamma$-ray detectors, the required properties on scintillation materials are a high $Z_{\text {eff }}$ $(>50)$ and a high light yield in both integration and pulse-counting type detectors. In the pulse-counting 
type detectors, a high energy resolution and a fast decay time are particularly required, while low afterglow is required in integration-type detectors. As mentioned above, in my opinion, the firstgeneration scintillators were simple chemical compounds, such as $\mathrm{NaI}$ and $\mathrm{CsI}$ and natural phosphor materials, including $\mathrm{CdWO}_{4}$ and $\mathrm{CaF}_{2}$, developed and used since the 1940s; second-generation scintillator was BGO, available since the 1970s. After the 1990s, third-generation scintillators, which are typically a combination of host and emission center type (e.g., Ce-doped LSO and LYSO), had started to be used. Thus, most state-of-the-art scintillators developed today are those doped with an emission center.

The trends of the third-generation scintillators have three streams: rare-earth silicate, rare-earth garnet and some halide materials. The root of rareearth silicate was Ce-doped $\mathrm{Gd}_{2} \mathrm{SiO}_{5}$ (GSO), ${ }^{90)}$ which was found by Hitachi Chemical, Japan. Inspired by this invention, Lu-substituted scintillators, such as LSO and LYSO, were developed in western countries, and these scintillators are now standards for detectors of PET. Unfortunately, the patent of GSO missed to include Lu-substituted materials, and the industrial market is now dominated by western countries, which have patents on LSO and LYSO. Thus, Japan is the origin of one of the three mainstreams in the scintillator field today. The scintillation properties of these Ce-doped silicates are characterized by a high light yield (10,000$30,000 \mathrm{ph} / \mathrm{MeV}$ ) and a fast scintillation decay (30$60 \mathrm{~ns}$ ) with blue emission appearing at around $430 \mathrm{~nm}$. These properties are suited for detectors in PET. Since Lu-based silicate scintillators have superior light yield $(20,000-30,000 \mathrm{ph} / \mathrm{MeV})$ than GSO (10,000 ph/MeV), most PET use LSO or LYSO. In order to improve the scintillation properties, Ca can be added as a co-dopant, ${ }^{92), 93)}$ which are now used in practical detectors. Following silicate materials with a composition of $R E_{2} \mathrm{SiO}_{5}$, where $R E$ denotes rare-earth elements, other materials with different chemical compositions of $R E_{2} \mathrm{Si}_{2} \mathrm{O}_{7}$ have also been investigated, and are called pysosilicate. Among the pyrosilicate scintillators, Ce-doped $\mathrm{Gd}_{2} \mathrm{Si}_{7} \mathrm{O}_{7}$ (GPS) was developed by groups at Hokkaido University and Hitachi Chemical, and it was reported to show a higher light yield than the LSO series and a fast decay of several ten ns. ${ }^{94), 95)}$ Following this work, La admixed GPS (LGPS) was found, ${ }^{96}$ ) which exhibited comparable scintillation properties as Ce-doped GPS $^{97), 98)}$ but are easier to be fabricated in single crystal. Unlike the case of $R E_{2} \mathrm{SiO}_{5}$ materials, a Lu- based composition $\left(\mathrm{Lu}_{2} \mathrm{Si}_{2} \mathrm{O}_{7}\right)$ (LPS $)^{99)}$ has worse scintillation properties than GPS in terms of the light yield and energy resolution. In addition to $R E_{2} \mathrm{SiO}_{5}$ and $R E_{2} \mathrm{Si}_{2} \mathrm{O}_{7}$, other chemical compositions, such as $R E_{9.33}\left(\mathrm{SiO}_{4}\right)_{6} \mathrm{O}_{2}$ and $\left(A E_{2} R E_{8}\right)\left(\mathrm{SiO}_{4}\right)_{6} \mathrm{O}_{2}$ ( $A E$ represents alkali earth elements) are also possible candidates of scintillators, ${ }^{100)}$ and are called apatite scintillators. Apatite scintillators have started to be investigated recently, ${ }^{100)-102)}$ and at present much less information concerning to scintillation properties of such apatite scintillators is available compared to other silicate compounds. Apatite scintillators are interesting, since the type of $\left(A E_{2} R E_{8}\right)\left(\mathrm{SiO}_{4}\right)_{6} \mathrm{O}_{2}$, especially, has two sites ( $A E$ and $R E$ ) to accommodate rare-earth dopant ions. I expect future studies will discover novel silicate scintillators.

Garnet materials of scintillators typically have chemical compositions of $R E_{3}(\mathrm{Al}, \mathrm{Ga})_{5} \mathrm{O}_{12}$, and some impurity ions are doped as emission centers. The root of the garnet materials for phosphor applications was $\mathrm{Y}_{3} \mathrm{Al}_{5} \mathrm{O}_{12}$ (YAG), which was developed in the 1960s for laser applications. ${ }^{103)}$ In the scintillator field, the scintillation properties of a Ce-doped YAG were investigated in the $1990 \mathrm{~s},{ }^{104), 105)}$ and it was then reported to exhibit intense and fast emission due to the $5 \mathrm{~d}-4 \mathrm{f}$ transitions of $\mathrm{Ce}^{3+}$. The Ce-doped YAG has been mainly used for charged-particle detectors, and it was attempted to substitute $\mathrm{Lu}$ for the $\mathrm{Y}$ (Cedoped LuAG) in order to achieve a higher detection efficiency for high-energy photons. ${ }^{106)}$ Instead of Lu, Gd-substitution was also considered, and at first, Ce-doped $(\mathrm{Gd}, \mathrm{Y})_{3} \mathrm{Al}_{5} \mathrm{O}_{12}$ (GYAG) was developed. ${ }^{107)}$ Further studies succeeded to fully replace by $\mathrm{Gd}$, and the Ce-doped $\mathrm{Gd}_{3}(\mathrm{Al}, \mathrm{Ga})_{5} \mathrm{O}_{12}$ (GAGG) was found to show distinct scintillation light yield $(\sim 46,000$ $\mathrm{ph} / \mathrm{MeV})$, and became a commercial product. ${ }^{36)}$ A few years ago, we achieved $70,000 \mathrm{ph} / \mathrm{MeV}$ by developing a Ce-doped GAGG ceramic, which had the highest light yield among the oxide scintillators. ${ }^{108)}$ We have continued to study Ce-doped garnet materials, and very recently, we discovered that Cedoped $\mathrm{Tb}_{3} \mathrm{Al}_{5} \mathrm{O}_{12}$ (TAG) also shows very promising scintillation properties: a high light yield of 57,000 $\mathrm{ph} / \mathrm{MeV}$ with a decay time of $38 \mathrm{~ns} .{ }^{109), 110)}$ Before this study, Ce-doped TAG was only considered in a thinfilm form, ${ }^{111)}$ and it was impossible to evaluate the scintillation light yield under $\gamma$-ray irradiation. Therefore, this discovery opens a new possibility to be considered as a host of garnet scintillators. An important property of Ce-doped garnet scintillators is the emission wavelength as well as the high light yield and fast decay. The peak emission wavelength 
typically appears at 500-550 nm, which matches the spectral sensitivity of Si-based photodetectors. At present, Ce-doped garnet scintillators are the only choice to be used with Si-PD, avalanche PD (APD) and Geiger-mode APD.

In the 2000s, it was also discovered that $\mathrm{Pr}^{3+}$ doped LuAG also showed a 5d-4f transition of $\mathrm{Pr}^{3+}{ }^{112)}$ Prior to this study in the 1990s, Pr-doped YAG was known to have a relatively high light yield, ${ }^{75), 113)}$ but further studies were not conducted. The emission wavelength of $\mathrm{Pr}^{3+}$ in garnet materials is near UV, so it is difficult to use with conventional photodetectors, such as PD, and PMT is difficult. This is the reason why Pr-doped garnet scintillators were not accepted in practical applications in spite of their relatively high light yield (10,000-20,000 ph/ $\mathrm{MeV})$, fast decay $(\sim 20 \mathrm{~ns})$ and high energy resolution $(4.3 \%$ at $\left.662 \mathrm{keV}) .{ }^{114}\right)$ For practical applications, Pr-doped garnet scintillators, photodetectors, which have a high quantum efficiency in the UV must be developed.

The last trend of $\mathrm{R} \& \mathrm{D}$ is a recent focus on halide scintillators. As mentioned above, the history of scintillators and scintillation detectors started with halide scintillators, such as NaI, CsI and $\mathrm{CaF}_{2}$, and $\mathrm{NaI}$ had become one of the standard scintillators. In order to develop a "next" NaI, continuous efforts have been made, since halide scintillators have a great potential to display a high light yield due to the relatively smaller band gap than that of common materials of oxide, fluoride and nitride. This trend also started from early in the 2000s at Delft University. Ce-doped $\mathrm{LaCl}_{3}{ }^{72}$ ) and $\mathrm{LaBr}_{3}{ }^{73)}$ were discovered, which have shown a very high light yield $(\sim 60,000 \mathrm{ph} / \mathrm{MeV})$ with a very high energy resolution $(3-4 \%$ at $662 \mathrm{keV})$. Before the discoveries of these materials, the highest light yield of scintillators for $\gamma$-ray detectors were at most 40,000-50,000 ph/ $\mathrm{MeV}$ by $\mathrm{NaI}$ and $\mathrm{CsI}$, and this discovery was quite sensational. Following these pioneering investigations, numerous researchers started to investigate many halide materials as potential scintillators, and some new materials were found. Among these newly developed scintillators, Eu-doped $\mathrm{SrI}_{2}{ }^{19), 38), 115)}$ became a commercial product for $\gamma$-ray detectors. Actually, Eu-doped $\mathrm{SrI}_{2}$ was invented in the mid20th century, ${ }^{116)}$ but no one paid any continuous attention on this material, possibly due to its featureless properties. However, owing to the recent progress of crystal growth technology, the crystal quality had improved, and the scintillation properties were dramatically enhanced (e.g., scintillation light yield of up to $120,000 \mathrm{ph} / \mathrm{MeV}$, energy resolution of $3 \%$ at $662 \mathrm{keV}$ and a decay time of around $1 \mu \mathrm{s}$ ). Since the main patent was lost in effect, many industrial suppliers of scintillators started to develop this material to productize, and the purpose was obviously the "next" NaI. At present, as matter of fact, it is not realistic for $\mathrm{LaBr}_{3}$ and $\mathrm{SrI}_{2}$ to become the next $\mathrm{NaI}$ because of its very high hygroscopic nature. These scintillators must be capsulated to avoid moisture, and the freedom of the detector design is strongly limited by the shape of the scintillators. Typically, products of $\mathrm{LaBr}_{3}$ and $\mathrm{SrI}_{2}$ are cut to 1-2 inches in diameter and 1-2 inches in height; other sizes are not available for most researchers who develop scintillation detectors.

As described above, conventional halide scintillators are very bright, but hygroscopic. Recently, some groups including the author's groups have started to search for non-hygroscopic halide scintillators. Within these few years, $\mathrm{Cs}_{2} \mathrm{HfCl}_{6}{ }^{117), 118)}$ was introduced as a promising alternative. This material was discovered by two independent studies by an American group and our group a coincidence by. $\mathrm{Cs}_{2} \mathrm{HfCl}_{6}$ is non-hygroscopic, and it includes $\mathrm{Hf}$ as a host constitution, so the cross-section to high energy photons is very high. The light yield was evaluated to be around 30,000 ph/MeV under $\gamma$-ray exposure with a few $\mu$ s decay time. With the knowledge of a similar compound, $\mathrm{Cs}_{2} \mathrm{ZrCl}_{6}$, the emission origin was blamed for the charge-transfer luminescence of the $\left[\mathrm{HfCl}_{6}\right]^{2-}$ anion complex. Motivated by this work, we have further developed non-hygroscopic halide scintillators, including $\mathrm{Tl}$ - and In-doped $\mathrm{CsCl},{ }^{119)} \mathrm{TlCdCl}_{3},{ }^{120}$ ) Tl- and Ce-doped $\mathrm{Cs}_{2} \mathrm{HfCl}_{6},{ }^{121}{ } \mathrm{Rb}_{2} \mathrm{HfCl}_{6},{ }^{122)} \mathrm{Ce}-$ doped $\mathrm{CsCaCl}_{3}{ }^{123)}$ and $\mathrm{TlMgCl}_{3} \cdot{ }^{124)}$ Among these newly developed scintillators, especially $\mathrm{TlMgCl}_{3}$ shows the most promising properties of a high light yield $(46,000 \mathrm{ph} / \mathrm{MeV})$, a high energy resolution $(5 \%$ at $662 \mathrm{keV}$ ) and a relatively fast decay (60 ns).

Recent R\&D of scintillators for neutron detectors. Scintillators for neutron detectors have been attracting much attention recently due to a decreasing supply of ${ }^{3} \mathrm{He}$ gas, which has been a fundamental of conventional neutron detectors over the past decades. ${ }^{125), 126)}$ As an alternative to ${ }^{3} \mathrm{He}$ gas, many efforts have been made to develop scintillators containing ${ }^{6} \mathrm{Li}$ and ${ }^{10} \mathrm{~B}$, which have high interaction probabilities against thermal neutrons. Before the ${ }^{3} \mathrm{He}$ problem, the applications of scintillators for neutron detectors were not many, and this is a new subject of scintillator research. For this purpose, many scintillators were developed, and ${ }^{6} \mathrm{Li}$-enriched 
elpasolite and $\mathrm{LiCaAlF}_{6}$ scintillators have reached to the commercial stage. The former one, elpasolite, has a chemical composition of $\mathrm{Cs}_{2} A M R E(\mathrm{Cl}, \mathrm{Br})_{6}$, where $A M$ means alkali metal elements, and $\mathrm{Li}$ is chosen to detect neutrons. The root of the elpasolite was also at Delft University, ${ }^{127)}$ but the R\&D for practical applications was conducted in the U.S. Up to now, many elpasolite materials have been developed, and Ce-doped $\mathrm{Cs}_{2} \mathrm{LiYCl}_{6}$ (CLYC) demonstrated the best performance as a neutron detector. ${ }^{128)}$ Although CLYC and other elpasolite scintillators have a high $\alpha / \beta$ ratio and distinct functions of a pulse-shape discrimination of $\gamma$-rays and neutrons, a large degree of hygroscopicity is a disadvantage for practical applications, as for $\mathrm{LaBr}_{3}$ and $\mathrm{SrI}_{2}$. $\mathrm{LiCaAlF}_{6}$ has been developed by the author's groups for neutron detectors. ${ }^{39), 40)}$ The advantage of $\mathrm{LiCaAlF}_{6}$ is a nonhygroscopicity and a high scintillation light yield when $\mathrm{Eu}^{2+}$ is doped as an emission center. Pulseshape discrimination is possible when $\mathrm{Ce}^{3+}$ is doped. At present, the productization of ${ }^{6} \mathrm{Li}$-containing scintillators for neutron detectors has converged on these two scintillators.

Compared with ${ }^{6} \mathrm{Li},{ }^{10} \mathrm{~B}$ has a higher crosssection against thermal neutrons, but has lower Qvalue. Thus, it is difficult to develop a ${ }^{10} \mathrm{~B}$-based bright scintillator for neutron detectors. Up to now, the brightest ${ }^{10} \mathrm{~B}$-based bulk crystalline scintillator has been developed by us, which is Ce-doped $\mathrm{CaB}_{2} \mathrm{O}_{4}$, exhibiting $2,200 \mathrm{ph} / \mathrm{n}$ under neutron excitation. ${ }^{129)}$ The light yield must be improved for practical detector applications.

Recent R\&D of scintillators for charged particle detectors. Charged-particle detectors are mainly used for detecting $\alpha$-rays, which have a high interaction probability with most materials. In scintillation detectors for $\alpha$-rays, Ag-doped $\mathrm{ZnS}$ has been used historically. ${ }^{1)} \mathrm{ZnS}$ is the most famous of all scintillators because a $\mathrm{ZnS}$ screen was utilized in the famous Rutherford experiments employed to prove the existence of the atomic nucleus. Ag: ZnS is only available as a polycrystalline powder (visibly white), and applications are limited to thin screens made by, for example, spraying. Therefore, in spite of a high light yield of 90,000 photons/MeV, the energy resolution of $\mathrm{Ag}: \mathrm{ZnS}$ is not so good, except for some ideal detector geometries. Recently, scintillators for $\alpha$-ray detection have become highly demanded all over the world. In nuclear processing plants, uranium and plutonium are manufactured, that elements emit $\alpha$-rays, which should be monitored. ${ }^{130}$ ) They can contaminate in the human body and cause serious damage by internal exposure. Since the environment required to monitor $\alpha$-rays often comprise background $\gamma$-rays; scintillators for $\alpha$-ray detections must be insensitive to $\gamma$-rays. In addition, a high energy resolution is desired to distinguish from various radioisotopes. ${ }^{131)}$ Therefore, new scintillators for $\alpha$ ray detectors should require a high energy resolution. To achieve this resolution, the scintillator materials should have high transparence. Moreover, to avoid detecting background $\gamma$-rays and neutrons, scintillators must have an intermediate $Z_{\text {eff }}$, and thus the candidates are elements with $Z=10-30$. In order to develop novel scintillators for $\alpha$-ray detectors, we have focused on $\mathrm{ZnO}$ thin-film scintillators. Since the penetration depth of $\alpha$-rays is not so deep (around 10-20 $\mathrm{m}$ ), film scintillators are ideal. In addition, Zn has a low cross-section to $\gamma$-rays and neutrons. $\mathrm{Up}$ to now, we have developed some $\mathrm{ZnO}$ film scintillators, ${ }^{132)}$ and have demonstrated $\alpha$-ray real time imaging by using $\mathrm{ZnO}{ }^{133)}$

Unresolved problems. In scintillator-related fields, there are many unresolved problems in spite of a large number of practical applications. Here, I select some unresolved topics and discuss our most recent understandings of these phenomena along with some experimental results.

Positive hysteresis. In scintillation phenomena, there are many unresolved problems. One of the important problems involved in both basic science and detector applications is positive hysteresis. Positive hysteresis is defined as an enhancement of the scintillation light yield observed after a large amount of radiation exposure. This phenomenon is sometimes called by other names: radiation drift and bright burn. To my understanding, positive hysteresis is not a common phenomenon, and observations were reported only in selected materials, including Prdoped $\mathrm{Lu}_{2} \mathrm{Si}_{2} \mathrm{O}_{7}$ (LPS), ${ }^{134)}$ Tl-doped CsI, ${ }^{135)} \mathrm{Ce}-$ doped and $\mathrm{Ce} / \mathrm{Zr}$ co-doped $\mathrm{Gd}_{2} \mathrm{SiO}_{5}(\mathrm{GSO})$, ${ }^{136)} \mathrm{Ce}-$ doped $\mathrm{Gd}_{3}(\mathrm{Al}, \mathrm{Ga})_{5} \mathrm{O}_{12}$ (Ce:GAGG), ${ }^{137)}$ Tb-doped $\mathrm{SiO}_{2}$ glass ${ }^{138)}$ and $\mathrm{Ce} / \mathrm{Nd}$ co-doped $\mathrm{YPO}_{4}{ }^{139)} \mathrm{On}$ one hand, from a physics point of view, the origin of positive hysteresis is currently under discussion, and at least it has been considered that carrier traps ${ }^{138), 139)}$ and the generation of new excitation bands above the band gap energy ${ }^{136), 137)}$ are important. On the other hand, from the viewpoint of practical applications, positive hysteresis needs to be suppressed, or corrected, by the readout electronics or software, since it can cause some ghosts in a radiation image. In addition, it should be noted that two different measurements were previously considered 


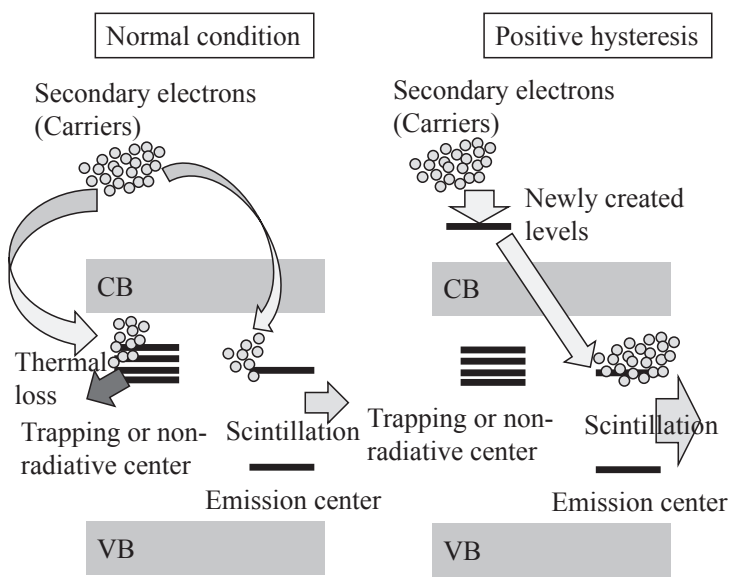

Fig. 13. Schematic drawings of energy transport processes under a normal condition (left) and a positive hysteresis condition (right).

to determine the scintillation light yield involved in this problem: by the pulse-height spectrum ${ }^{136), 137)}$ and radioluminescence. ${ }^{134), 138), 139)}$ In order to discuss the light yield of the scintillator, any pulse-height analysis should be conducted as mentioned in the introduction, though some groups still continue to use the radioluminescence intensity.

In our most recent study, ${ }^{140)}$ we found that $\mathrm{Pr}$ doped LPS did not show any positive hysteresis (confirmed by the pulse height analyses), and we thought that the positive hysteresis of the pioneering report in Pr-doped LPS may have been be affected by radiation-induced afterglow (their study was based on a radioluminescence analysis). Therefore, in my opinion, the materials confirmed to show positive hysteresis up to now are CsI, GSO and GAGG. Figure 13 shows schematic drawings of the energy transportation processes under the normal and the positive hysteresis conditions. In the normal condition, many secondary electrons are generated by ionizing radiation exposure, and some secondary electrons (energies) are transported to the emission center, while other carriers (energies) are transferred to trapping or non-radiative centers. In the positive hysteresis condition, some of the secondary electrons (energies) are captured at newly created energy levels, and then efficiently transferred to the emission center directly. In the examples of CsI, GSO and GAGG, the light yield enhancement was at most $20 \%$. Possible origin of the newly created energy levels would be anion vacancies, since such a vacancy typically appears upon large-dose exposure. If the origin of the positive hysteresis is understood, then we would be able to control the light-yield enhance- ment phenomenon. For example, if the anion vacancy is the origin of positive hysteresis, we should consider including stable anion vacancies by, for example, synthesizing in a strong reducing environment or exposing to a large dose to obtain bright scintillator products.

Co-doping of non-luminescent ions. Recently, the co-doping of ions that have no luminescence energy levels has attracted much attention to improve the scintillation properties. The attempts have been made to improve an enhancement of the light yield and to suppress the slow component of scintillation decay. The most common example is $\mathrm{Ca}^{2+}$ and $\mathrm{Ce}^{3+}$ co-doped LSO. Here, the light yield and energy resolution have been improved, and a suppression of the slow decay component was reported. ${ }^{92), 93)}$ In $\mathrm{LSO}$, there are two $\mathrm{Lu}^{3+}$ sites that can accommodate $\mathrm{Ce}^{3+}$ ions, which shows fast emission at one site and slow emission at the other. The origin of this improvement in LSO can be understood by hypothesizing that the $\mathrm{Ce}^{3+}$ ions were selectively embedded at the former sites by codoping, so the slow emission was suppressed. ${ }^{92)}$ In addition, it was pointed out that individual difference of the $\mathrm{Ce}^{3+} / \mathrm{Ce}^{4+}$ ratio was considerably large in LSO samples, ${ }^{141)}$ and such a ratio may be related to $\mathrm{Ca}^{2+}$ co-doping.

Ce- and Eu-doped $\mathrm{LiCaAlF}_{6}$ crystal scintillators have been developed recently by the author and collaborators, 39$), 40), 142), 143$ ) and they have become commercial products by Tokuyama Corp. for thermal neutron scintillation detectors. Especially, Eu-doped $\mathrm{LiCaAlF}_{6}$ is known to have the highest light yield ( $\sim 30,000 \mathrm{ph} / \mathrm{n})$ under neutron irradiation among nonhygroscopic materials. During the R\&D processes, we found that the light yield can be enhanced by codoping with alkali metal elements. ${ }^{144)}$ Alkali metal ions including $\mathrm{Na}, \mathrm{K}, \mathrm{Rb}$ and $\mathrm{Cs}$ are known to show no luminescence features. We discovered that, when $\mathrm{Na}$ is included to Eu-doped $\mathrm{LiCaAlF}_{6}$, the scintillation light yield was enhanced to $\sim 42,000 \mathrm{ph} / \mathrm{n}$. Historically, especially in laser fields, the charge imbalance of $\mathrm{Ce}^{3+}$ and $\mathrm{Ca}^{2+}$ in $\mathrm{Ce}$-doped $\mathrm{LiCaAlF}_{6}$ was compensated by an addition of $\mathrm{Na}^{+}$under the assumption that the $\mathrm{Ce}^{3+}$ ions would substitute for the $\mathrm{Ca}^{2+}$ sites. ${ }^{145)}$ Therefore, at that time, the same approach was considered to be nonsense for $\mathrm{Eu}^{2+}$ doped $\mathrm{LiCaAlF}_{6}$. Based on our experimental results, the effects of a charge balance cannot be applied at least to Eu-doped $\mathrm{LiCaAlF}_{6}$. In order to clarify the origin, we observed the excitation spectra of Eu and alkali metal co-doped $\mathrm{LiCaAlF}_{6}$ at the synchrotron 


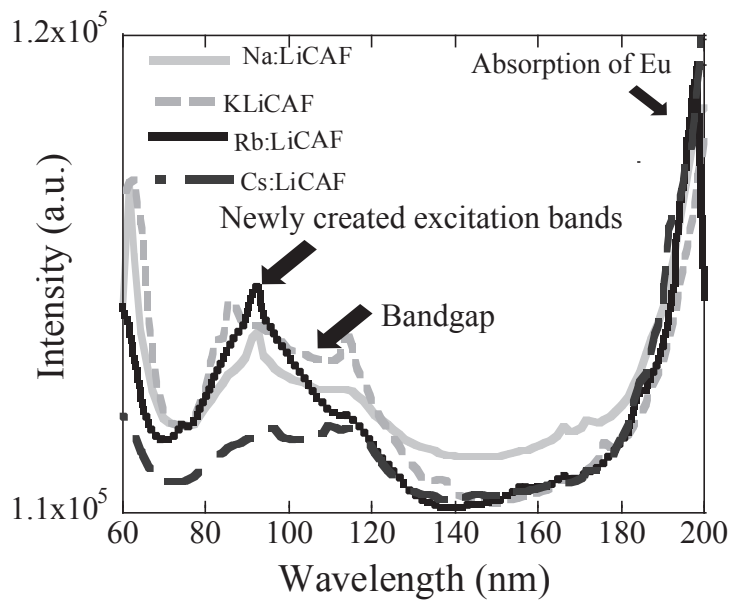

Fig. 14. Excitation spectra of Eu and alkali metal (Na, K, Rb and $\mathrm{Cs}$ ) co-doped $\mathrm{LiCaAlF}_{6}$ crystalline scintillators.

facility (UVSOR, Japan). Figure 14 shows the excitation spectra of Eu-doped $\mathrm{LiCaAlF}_{6}$ incorporated with $\mathrm{Na}, \mathrm{K}, \mathrm{Rb}$ and $\mathrm{Cs}$. In addition to the band gap $(\sim 110 \mathrm{~nm})$ and the absorption due to $\mathrm{Eu}$, a new excitation band appeared at around $80-100 \mathrm{~nm}$ in these materials. Actually, this excitation band was observed in undoped $\mathrm{LiCaAlF}_{6}$ at very low temperatures, and the highlight of this work was the appearance of this band at room temperature. The role of co-doping with alkali metal elements is to enhance some kinds of defects associated with the $\mathrm{LiCaAlF}_{6}$ host. My idea is that the same interpretations as in Fig. 13 can be applied to understand this phenomenon. The enhancement of the light yield by co-doping with alkali metal is around $30 \%$, and the ratio of the newly created energy level to the band gap energy is $1.2-1.3$. By opening this newly created path, the energy transfer efficiency was improved by $20-30 \%$ on average. In the case of Eu-doped $\mathrm{LiCaAlF}_{6}$, the order of the effectiveness by co-doping was $\mathrm{Na}>\mathrm{Rb}>\mathrm{Cs}>\mathrm{K}$, while the best performance was observed by co-doping with $\mathrm{K}$ in the case of $\mathrm{LiSrAlF}_{6}$.

A similar light yield enhancement by co-doping was also observed in $\mathrm{Mg}^{2+}$ co-doped $\mathrm{Lu}_{3} \mathrm{Al}_{5} \mathrm{O}_{12} \cdot{ }^{146}$ ) Following this study, other garnet scintillators have been studied by mainly the same group, but a similar enhancement effect was not observed. Thus, among garnet scintillators, a light yield enhancement can be possible in $\mathrm{Lu}_{3} \mathrm{Al}_{5} \mathrm{O}_{12}$ by a coincident combination of $\mathrm{Ce}^{3+}$ and $\mathrm{Mg}^{2+}$. The origin of this phenomenon was considered to be the generation of $\mathrm{Ce}^{4+}$ by doping with $\mathrm{Mg}^{2+}$, and the presence of $\mathrm{Ce}^{4+}$ was confirmed by a XANES (X-ray absorption near edge structure) analysis. Although some groups use this hypothesis, to my understanding, this model has not been confirmed yet, since the presented data are only the PL spectrum and XANES. In order to approve the model logically, it is necessary to confirm the following two points in addition to the presence of $\mathrm{Ce}^{4+}$. One is that the main energy-transfer process for $\mathrm{Ce}^{3+}$ ions is a sequential charge transfer, and not energy transfer from some relaxed excited states in the host to the $\mathrm{Ce}^{3+}$ ions. The second is that electron capture by $\mathrm{Ce}^{4+}$ ions is faster and more efficient than hole capture by $\mathrm{Ce}^{3+}$ ions. Recently, one of the discoverer groups denied this hypothesis and reported in some conferences and literature. ${ }^{147)}$ In my opinion, some groups use this hypothesis conclusively without experimental evidence of the dynamics, and it is an exaggeration. Further experiments are required to understand this phenomenon.

Introduction of aimed impurity phase. The scintillation light yield can be enhanced by introducing impurity phases. Actually, we have found this concept in Ce-doped GAGG ceramics. ${ }^{108)}$ In a GAGG crystal of the single phase, the scintillation light yield is known to be $46,000 \mathrm{ph} / \mathrm{MeV}$. In contrast, by including a few $\%$ of the perovskite phase, the light yield was enhanced up to $70,000 \mathrm{ph} / \mathrm{MeV}$. ${ }^{108)}$ Figure 15 illustrates my understanding of this phenomenon. I think the impurity phase works something like a bypass, and it suppresses the energy dissipation during transfer. Although the light yield could be improved by introducing the impurity phase, the energy resolution degraded because the material was no longer homogeneous on a microscopic scale.

Maybe the same idea is applicable to the positive hysteresis and co-doping with non-luminescent ions, because some "impurities" are included in the latter two cases as vacancies and impurity ions, respectively. These ideas of interpretation came up from the relation between the defect and scintillation light yield. In most scientific fields, including semiconductor and laser physics, the creation of defects in materials should be avoided as much as possible since they degrade the device performance. However, in scintillators, we have proved experimentally that a certain degree of defect concentration is required to achieve a high light yield. In an experiment, we prepared Pr-doped $\mathrm{Lu}_{3} \mathrm{Al}_{5} \mathrm{O}_{12}$ with the same amount of $\mathrm{Pr}$, but different defect concentrations by controlling the synthesis processes, and evaluated the concentration of defects by an X-ray rocking curve and scintillation light yield under ${ }^{137} \mathrm{Cs} \gamma$-rays exposure. When we plotted the light yield as a 


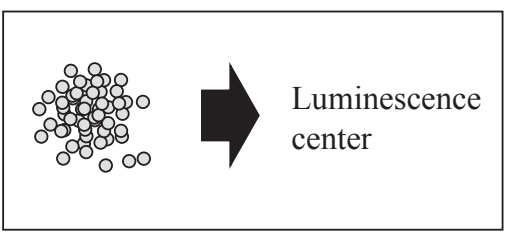

Main phase

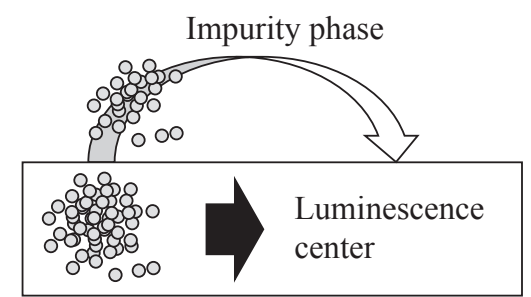

Main phase

Fig. 15. Schematic drawings of secondary electrons transported in a single-phase material (left) and a mixture of the main and impurity phases (right).

function of the defect concentrations, deduced from the X-ray rocking curve analysis, it showed a convex quadratic function feature with a clear peak. ${ }^{148)}$ From this result, I have noticed that ideal crystals (with no defects) are not preferred for scintillator uses, and that the inclusion of some defects or impurities is necessary. Similar work was done to compare between ceramic and crystal forms of undoped $\mathrm{Y}_{3} \mathrm{Al}_{5} \mathrm{O}_{12}$ and $\mathrm{Lu}_{3} \mathrm{Al}_{5} \mathrm{O}_{12}$ scintillators, since the types and number of defects differ in the ceramic and crystal. ${ }^{149)}$ To understand the phenomenon and to control the scintillation light yield, further studies are required.

Excitation density effect. The excitation density (LET) effect can be observed in some scintillators. Frankly speaking, excitation by ionizing photons (X- and $\gamma$-rays) has a relatively lower excitation density compared with that of charged particles (e.g., $\alpha$-rays). The excitation density effect is typically observed by measuring the scintillation decay time profile and the emission spectrum. The most famous example is $\mathrm{BaF}_{2}$, which shows Auger free luminescence. The Auger free luminescence is also called core valence luminescence because the luminescence occurs by the recombination of carriers within the core and valence bands. The physical properties of Auger free luminescence are characterized by fast decay, and in the case of $\mathrm{BaF}_{2}$, it is around $0.8 \mathrm{~ns}$. This Auger free luminescence in $\mathrm{BaF}_{2}$ can be observed in high-energy photon and electron excitations, but it cannot be seen under $\alpha$-ray excitation. ${ }^{150)}$ The threshold of the excitation density to make the Auger free luminescence appear was investigated by controlling the excitation density of a cathode luminescence technique; the obtained value was $2 \times 10^{19} \mathrm{eV} / \mathrm{cm}^{3}$ in $\mathrm{BaF}_{2}{ }^{151)}$ The threshold value is unique to each material, and the threshold was around $10^{19} \mathrm{eV} / \mathrm{cm}^{3}$. Although there are no confirmed theories, the quenching of secondary electrons would occur when the excitation density becomes large. Some luminescence transitions, especially Auger free luminescence, is very sensitive to LET, and such a quenching due to the interactions of secondary electrons is observed.

An important aspect of the excitation density effect for practical detector applications is a discrimination of ionizing radiations. The most common technique is pulse shape discrimination, which uses the difference of the scintillation decay profile (pulse shape) under high-energy photon and chargedparticle excitations. A common example is ${ }^{6} \mathrm{Li}$-based scintillators for thermal neutron detectors. By using the difference of the pulse shapes under $\gamma$-rays and $\alpha$ rays, caused by the ${ }^{6} \mathrm{Li}(\mathrm{n}, \alpha)^{3} \mathrm{H}$ reaction, the neutron and $\gamma$-ray induced events can be discriminated. Imagine some typical situations where neutron detectors are used. One of the common situations is around a nuclear reactor. The status of a nuclear reaction can be monitored by measuring neutrons generated by nuclear reactions, and in this situation, a large number of background $\gamma$-rays are also detected by scintillation detectors. In such a situation, the pulse-height discrimination is used in order to separate the signals by $\gamma$-rays and neutrons and to monitor the status of the nuclear reactor precisely. Common scintillators possessing the functionalities of pulse discrimination are $\mathrm{LiCaAlF}_{6}{ }^{152}$ ) and elpasolite ${ }^{153)}$ materials. Pulse-shape discrimination may be possible by employing some organic materials, ${ }^{154)}$ but the radiation tolerance is a problem in organic scintillators. Concerning future prospects, if the excitation density effect is fully understood, the pulse-shape discrimination technique can be applied for other ionizing radiations in practical applications.

Complementary relationship. As mentioned in the introduction, most of the basic physics of scintillation is still unclear in spite of a large number of practical applications. Especially, the important properties to be understood are the scintillation light yield and the dynamics (rise and decay of scintillation). I have particular interest in the former phenomenon. In other words, I am eager to know why some materials emit bright scintillation and some 
others do not. In my opinion, one of the key points is to comprehensively consider both scintillation and dosimetric properties, since these processes share some common aspects as shown in Fig. 3.

Historically, scintillators and dosimeter materials have been investigated and developed by different communities due to the differences of detection techniques and measurement time scales, while their purpose are the same: to detect ionizing radiation by luminescent materials. However, if we assume energy conservation, the scintillation and OSL/TSL properties can be connected, and they should be complementarily related. Considering the total energy of the scintillation output per incident radiation energy, an immediate conclusion is that only a small fraction of the radiation energy is used for luminescence. Here, a simple question may arise: 'why some scintillators are bright and the others are not?' In other words, where has the remaining energy gone? I would answer that some portion (maybe not all) of the remaining energy is stored in the material, and that it can be released by stimulation (OSL or TSL). Also, it is possible that another amount remaining energy is converted to thermal energy, which is used in the calorimeter for radiation detection. Therefore, we consider that the scintillation and OSL/TSL properties can be complementarily related, and understanding of this relation will be a great benefit for the future development of scintillator/dosimeter and our understanding of the scintillation light yield. Actually, we proposed a hypothesis that the luminescence intensities of scintillation and dosimeter are complementarily related, assuming the energy conservation law, and we tested the hypothesis experimentally. If materials are not bright in scintillation, they should effectively store absorbed energy and should show strong luminescence as dosimeters (TSL or OSL), and vice versa. Recently, this hypothesis was confirmed experimentally in Ce-doped $\mathrm{CaF}_{2}$, Eu-doped $\mathrm{LiCaAlF}_{6}$ and Pr-doped $\mathrm{Lu}_{3} \mathrm{Al}_{5} \mathrm{O}_{12}$ crystals and ceramics. ${ }^{155), 156)}$ Figure 16 demonstrates a relationship between the scintillation light yield and OSL intensity of $0.1-20 \%$ Ce-doped $\mathrm{CaF}_{2}$. With increasing the concentration of $\mathrm{Ce}$, the scintillation light yield decreased while the OSL intensity increased. The degradation of the light yield of highly Ce-doped $\mathrm{CaF}_{2}$ may be considered to be due to concentration quenching. However, it is not the present case in which most of the energy was stored in those heavily doped materials. Such a systematic study based on energy conservation is a conventional approach in high-energy physics, and I would like to find the key

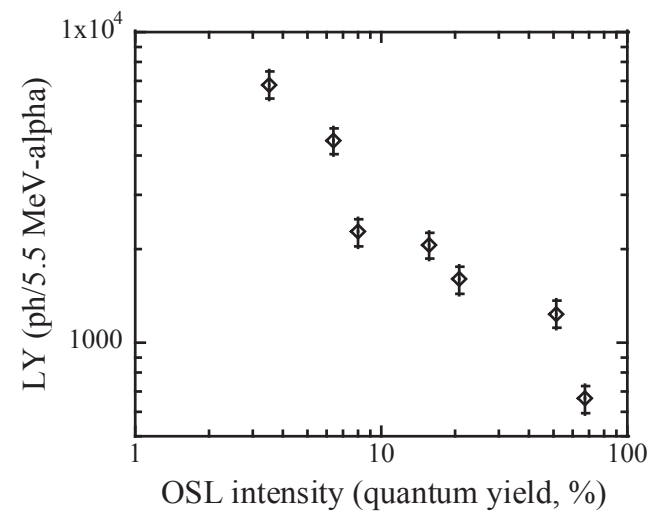

Fig. 16. Relationship between the scintillation light yield under $5.5 \mathrm{MeV} \alpha$-ray excitation and the OSL intensity after $1 \mathrm{~Gy}$ X-ray exposure in $0.1-20 \% \mathrm{Ce}$ doped $\mathrm{CaF}_{2}$ crystals. The data are taken from past experiments. ${ }^{156)}$

for understanding the scintillation light yield by systematic investigations with many different materials, particularly by focusing on the scintillation and storage luminescence properties together.

\section{Summary}

The basic properties of scintillators have been explained especially for applications in scintillation detectors, and a number of scintillators used in practical applications today introduced. In addition, state-of-the-art scintillators and scintillation detectors currently in the R\&D phase were reviewed. Finally, some unresolved problems were pointed out, and my interpretations based on experimental results explained.

\section{Acknowledgement}

This work was supported by a Grant in Aid for Young Scientists (B)-21760705 and (A)-23686135, a Grant in Aid for Young Scientists Challenging Exploratory Research-23656584, Grant-in-Aid for Scientific Research (A)-26249147 and (A) $17 \mathrm{H} 01375$ from the Ministry of Education, Culture, Sports, Science and Technology of Japan (MEXT) and partially by JST Development of advanced measurement and analysis systems (Sentan) and Adaptable and Seamless Technology Transfer Program through Target-driven R\&D (A-step). Partial assistance from the Yazaki Memorial Foundation for Science and Technology, Hitachi Metals Materials Science Foundation, Shimadzu Sci. Foundation, JFE 21st Century Foundation, The Mazda Foundation, Kato Foundation for Promotion of Science, and Nippon Sheet Glass Foundation for Materials Science and Engineering, Tokuyama Science foundation, The Murata 
Science Foundation, Kansai Research Foundation for technology promotion, The Kazuchika Okura Memorial Foundation, Inamori Foundation, Suzuki Foundation, Iketani Science and Technology Foundation, The Taisei Foundation, SEI Group CSR Foundation and The Asahi Glass Foundation, are also gratefully acknowledged. The Cooperative Research Project of Research Institute of Electronics, Shizuoka University is also acknowledged.

\section{References}

1) Knoll, G. (2000) Radiation Detection and Measurement. Wiley \& Sons, Hoboken.

2) Rodniy, P.A. (1997) Physical Processes in Inorganic Scintillators. CRC Press, Florida.

3) Birks, J.B. (1964) The Theory and Practice of Scintillation Counting. Pergamon Press, Oxford.

4) Koshimizu, M., Asai, K. and Shibata, H. (2001) Study on diffusion characteristics of the excited carriers in electron-hole plasma in GaAs using high-energy ions. J. Lumin. 94-95, 407-411.

5) Mckeever, S.W.S. (1985) Thermoluminescence of Solids. Cambridge University Press, Cambridge.

6) Yukihara, E.G. and McKeever, S.W.S. (2011) Optically Stimulated Luminescence: Fundamentals and Applications. Wiley, New York.

7) Yanagida, T., Fujimoto, Y., Watanabe, K., Fukuda, K., Kawaguchi, N., Miyamoto, Y. et al. (2014) Scintillation and optical stimulated luminescence of Ce doped $\mathrm{CaF}_{2}$. Radiat. Meas. 71, 162-165.

8) Yanagida, T. (2016) Ionizing radiation induced emission: scintillation and storage-type luminescence. J. Lumin. 169, 544-548.

9) Yanagida, T., Yoshikawa, A., Yokota, Y., Kamada, K., Usuki, Y., Yamamoto, S. et al. (2010) Development of Pr:LuAG scintillator array and assembly for positron emission mammography. IEEE Trans. Nucl. Sci. 57, 1492-1495.

10) Totsuka, D., Yanagida, T., Fukuda, K., Kawaguchi, N., Fujimoto, Y., Yokota, Y. et al. (2011) Performance test of $\mathrm{Si}$ PIN photodiode line scanner for thermal neutron detection. Nucl. Instrum. Methods Phys. Res. A 659, 399-402.

11) Yanagida, T., Fujimoto, Y., Kurosawa, S., Kamada, K., Takahashi, H., Fukazawa, Y. et al. (2013) Temperature dependence of scintillation properties of bright oxide scintillators for well-logging. Jpn. J. Appl. Phys. 52, 076401.

12) Mannes, D., Schmid, F., Frey, J., Schmidt-Ott, K. and Lehmann, E. (2015) Combined Neutron and $\mathrm{X}$-ray imaging for non-invasive investigations of cultural heritage objects. Phys. Procedia 69, 653660.

13) Kokubun, M., Abe, K., Ezoe, Y., Fukazawa, Y., Hong, S., Inoue, H. et al. (2004) Improvements of the Astro-E2 Hard X-ray Detector (HXD-II). IEEE Trans. Nucl. Sci. 51, 1991-1996.

14) Ito, T., Yanagida, T., Sato, M., Kokubun, M., Takashima, T., Hirakuri, S. et al. (2007) A 1- dimensional gamma-ray position sensor based on GSO:Ce scintillators coupled to a Si strip detector. Nucl. Instrum. Methods Phys. Res. A 579, 239-242.

15) Robbins, D.J. (1980) On predicting the maximum efficiency of phosphor systems excited by ionizing radiation. J. Electrochem. Soc. 127, 2694-2702.

16) Lempicki, A., Wojtowicz, A.J. and Berman, E. (1993) Fundamental limits of scintillator performance. Nucl. Instrum. Methods Phys. Res. A 333, 304-311.

17) Rodnyi, P.A., Dorenbos, P. and van Eijk, C.W.E. (1995) Energy loss in inorganic scintillators. Phys. Status Solidi (c) 187, 15-29.

18) Dorenbos, P. (2002) Light output and energy resolution of $\mathrm{Ce}^{3+}$-doped scintillators. Nucl. Instrum. Methods Phys. Res. A 486, 208-213.

19) Sturm, B.W., Cherepy, N.J., Drury, O.B., Thelin, P.A., Fisher, S.E., O'Neal, S.P. et al. (2011) Characteristics of undoped and europium-doped $\mathrm{SrI}_{2}$ scintillator detectors. 2011 IEEE Nuclear Science Symposium and Medical Imaging Conference (SS/MIC 2011) 7.

20) Pyrlik, J., Atiya, M., Broemmelsiek, D., Hamacher, Th., Ispiryan, M., Korpar, S. et al. (1998) Aging measurements of a TMAE based photon detector for the HERA-B RICH. Nucl. Instrum. Methods Phys. Res. A 414, 170-181.

21) Yanagida, T. (2013) Study of rare-earth doped scintillators. Opt. Mater. 35, 1987-1992.

22) Yanagida, T., Fujimoto, Y., Kamada, K., Totsuka, D., Yagi, H., Yanagitani, T. et al. (2012) Scintillation properties of transparent ceramic Pr:LuAG for different Pr concentration. IEEE Trans. Nucl. Sci. 59, 2146-2151.

23) van Loef, E.V.D., Dorenbos, P., van Eijk, C.W.E., Krämer, K. and Güdel, H.U. (2001) High-energyresolution scintillator: $\mathrm{Ce}^{3+}$ activated $\mathrm{LaBr}_{3}$. Appl. Phys. Lett. 79, 1573.

24) Alekhin, M.S., de Haas, J.T.M., Khodyuk, I.V., Krämer, K.W., Menge, P.R., Ouspenski, V. et al. (2013) Improvement of $\gamma$-ray energy resolution of $\mathrm{LaBr}_{3}: \mathrm{Ce}^{3+}$ scintillation detectors by $\mathrm{Sr}^{2+}$ and $\mathrm{Ca}^{2+}$ co-doping. Appl. Phys. Lett. 102, 161915.

25) Henderson, B. and Imbush, G.F. (1989) Optical Spectroscopy of Inorganic Solids. Clarendon Press, Oxford.

26) Dorenbos, P. (2010) Fundamental limitations in the performance of $\mathrm{Ce}^{3+}-, \mathrm{Pr}^{3+}$, and $\mathrm{Eu}^{2+}$-activated scintillators. IEEE Trans. Nucl. Sci. 57, 11621167.

27) Yanagida, T., Fujimoto, Y., Yamaji, A., Kawaguchi, N., Kamada, K., Totsuka, D. et al. (2013) Study of the correlation of scintillation decay and emission wavelength. Radiat. Meas. 55, 99-102.

28) Röntgen, W.C. (1895) On a new kind of rays. Nature 53, 274-276.

29) Sakai, E. (1987) Recent measurements on scintillator-photodetector systems. IEEE Trans. Nucl. Sci. 34, 418-422.

30) Holl, I., Lorenz, E. and Mageras, G. (1988) A 
measurement of the light yield of common inorganic scintillators. IEEE Trans. Nucl. Sci. 35, 105-109.

31) Shimizu, Y., Minowa, M., Suganuma, W. and Inoue, Y. (2006) Dark matter search experiment with $\mathrm{CaF}_{2}(\mathrm{Eu})$ scintillator at Kamioka Observatory. Phys. Lett. B 633, 195-200.

32) Grabmaier, B.C. (1984) Crystal scintillators. IEEE Trans. Nucl. Sci. 31, 372-376.

33) Weber, M.J. and Monchamp, R.R. (1973) Luminescence of $\mathrm{Bi}_{4} \mathrm{Ge}_{3} \mathrm{O}_{12}$ - spectral and decay properties. J. Appl. Phys. 44, 5495-5499.

34) Melcher, C.L. and Schweitzer, J.S. (1992) Ceriumdoped lutetium oxyorthosilicate - a fast, efficient new scintillator. IEEE Trans. Nucl. Sci. 39, 502505.

35) Pidol, L., Kahn-Harari, A., Viana, B., Virey, E. Ferrand, B., Dorenbos, P. et al. (2004) High efficiency of lutetium silicate scintillators, Cedoped LPS, and LYSO crystals. IEEE Trans. Nucl. Sci. 51, 1084-1087.

36) Kamada, K., Endo, T., Tsutumi, K., Yanagida, T., Fujimoto, Y., Fukabori, A. et al. (2011) Composition engineering in cerium-doped $(\mathrm{Lu}, \mathrm{Gd})_{3^{-}}$ $(\mathrm{Ga}, \mathrm{Al})_{5} \mathrm{O}_{12}$ single-crystal scintillators. Cryst. Growth Des. 11, 4484-4490.

37) Yanagida, T., Itoh, T., Takahashi, H., Hirakuri, S., Kokubun, M., Makishima, K. et al. (2007) Improvement of ceramic $\mathrm{YAG}(\mathrm{Ce})$ scintillators to $(\mathrm{YGd})_{3} \mathrm{Al}_{5} \mathrm{O}_{12}(\mathrm{Ce})$ for gamma-ray detectors. Nucl. Instrum. Methods Phys. Res. A 579, 23-26.

38) Yanagida, T., Koshimizu, M., Okada, G., Kojima, T., Osada, J. and Kawaguchi, N. (2016) Comparative study of nondoped and Eu-doped $\mathrm{SrI}_{2}$ scintillator. Opt. Mater. 61, 119-124.

39) Yanagida, T., Yoshikawa, A., Yokota, Y., Maeo, S., Kawaguchi, N., Ishizu, S. et al. (2009) Crystal growth, optical properties, and alpha-ray responses of $\mathrm{Ce}$ doped $\mathrm{LiCaAlF}_{6}$ for different $\mathrm{Ce}$ concentration. Opt. Mater. 32, 311-314.

40) Yanagida, T., Kawaguchi, N., Fujimoto, Y., Fukuda, K., Yokota, Y., Yamazaki, A. et al. (2011) Basic study of Europium doped $\mathrm{LiCaAlF}_{6}$ scintillator and its capability for thermal neutron imaging application. Opt. Mater. 33, 1243-1247.

41) Yanagida, T., Fujimoto, Y., Miyamoto, M. and Sekiwa, H. (2014) Optical and scintillation properties of Cd doped ZnO film. Jpn. J. Appl. Phys. 53, 02BC13.

42) Yanagida, T., Fujimoto, Y., Yamanoi, K., Kano, M., Wakamiya, A., Kurosawa, S. et al. (2012) Optical and scintillation properties of bulk $\mathrm{ZnO}$ crystal. Phys. Status Solidi (c) 9, 2284-2287.

43) Watanabe, K., Koshimizu, M., Fujimoto, Y., Hayashi, Y., Takizawa, H., Yanagida, T. et al. (2017) Scintillation properties of high-pressuresynthesized $\mathrm{ZnO}$ ceramics. Radiat. Meas. 106, 146-150. doi: 10.1016/j.radmeas.2016.12.007.

44) Yanagida, T., Fujimoto, Y. and Koshimizu, M. (2014) Evaluation of scintillation properties of GaN. e-J. Surf. Sci. Nanotechnol. 12, 396-399.

45) Yanagida, T., Okada, G., Kato, T., Nakauchi, D. and Yanagida, S. (2016) Fast and high light yield scintillation in $\mathrm{Ga}_{2} \mathrm{O}_{3}$ semiconductor material. Appl. Phys. Express 9, 042601.

46) Usui, Y., Oya, T., Okada, G., Kawaguchi, N. and Yanagida, T. (2017) Development of $\mathrm{Ga}_{2} \mathrm{O}_{3}$ single crystalline semiconductor scintillator doped with Ce. Optik 143, 150-157.

47) Usui, Y., Oya, T., Okada, G., Kawaguchi, N. and Yanagida, T. (2017) Comparative study of scintillation and optical properties of $\mathrm{Ga}_{2} \mathrm{O}_{3}$ doped with $\mathrm{ns}^{2}$ ions. Mater. Res. Bull. 90, 266272 .

48) Laval, M., Moszynski, M., Allemand, R., Cormoreche, E., Guinet, P., Odru, R. et al. (1983) Barium fluoride inorganic scintillator for subnanosecond timing. Nucl. Instrum. Methods Phys. Res. 206, 169-176.

49) Shendrik, Y.R., Radzhabov, A. and Nepomnyashchikh, A.I. (2013) Scintillation properties of $\mathrm{SrF}_{2}$ and $\mathrm{SrF}_{2}-\mathrm{Ce}^{3+}$ crystals. Tech. Phys. Lett. 39, 587-590.

50) Mikhailik, V.B., Kraus, H., Imber, J. and Wahl, D. (2006) Scintillation properties of pure $\mathrm{CaF}_{2}$. Nucl. Instrum. Methods Phys. Res. A 566, 522-525.

51) Yanagida, T., Kawaguchi, N., Fujimoto, Y., Fukuda, K., Watanabe, K., Yamazaki, A. et al. (2013) Scintillation properties of $\mathrm{LiF}_{-} \mathrm{SrF}_{2}$ and LiF-CaF 2 eutectic. J. Lumin. 144, 212-216.

52) Yanagida, T., Fujimoto, Y., Fukuda, K., Kawaguchi, N., Watanabe, K., Yamazaki, A. et al. (2013) Ce-doped LiF-SrF ${ }_{2}$ eutectic scintillators for thermal neutron detection produced at different solidification rates. Opt. Mater. 35, 1449-1554.

53) Itoh, M. and Kamada, M. (2001) Comparative study of Auger-free luminescence and valenceband photoemission in wide-gap materials. J. Phys. Soc. Jpn. 70, 3446-3451.

54) Yanagida, T., Kawaguchi, N., Fujimoto, Y., Sugiyama, M., Furuya, Y., Yokota, Y. et al. (2010) Growth and scintillation properties of $\mathrm{BaMgF}_{4}$. Nucl. Instrum. Methods Phys. Res. A 621, 473-477.

55) Moszynski, M., Allemand, R., Odru, M.L.R. and Vacher, J. (1983) Recent progress in fast timing with CsF scintillators in application to timeof-flight positron tomography in medicine. Nucl. Instrum. Methods Phys. Res. 205, 239-249.

56) Yahaba, N., Koshimizu, M., Yan, S., Yanagida, T., Fujimoto, Y., Haruki, R. et al. (2014) X-ray detection capability of a $\mathrm{Cs}_{2} \mathrm{ZnCl}_{4}$ single-crystal scintillator. Appl. Phys. Express 7, 062602.

57) Schotanus, P., van Eijk, C.W.E., Hollander, R.W. and Pijpelink, J. (1985) Temperature dependence of $\mathrm{BaF}_{2}$ scintillation light yield. Nucl. Instrum. Methods Phys. Res. A 238, 564-565.

58) Yanagida, T., Fujimoto, Y., Koshimizu, M. and Fukuda, K. (2015) Scintillation properties of $\mathrm{CdF}_{2}$ crystal. J. Lumin. 157, 293-296.

59) Anderson, D.F. (1989) Properties of the highdensity scintillator cerium fluoride. IEEE Trans. Nucl. Sci. 36, 137-140.

60) Gong, W., Wu, Y., Zhang, R. and Gaune-Escard, M. 
(2012) Phase equilibrium in lanthanide halide systems: assessment of $\mathrm{CeBr}_{3}$ and $\mathrm{MBr}-\mathrm{CeBr}_{3}$ systems (M=Li,Na,K,Rb,Cs). Calphad 36, 44-51.

61) Kato, T., Okada, G. and Yanagida, T. (2016) Optical, scintillation and dosimeter properties of $\mathrm{MgO}$ transparent ceramic and single crystal. Ceram. Int. 42, 5617-5622.

62) Futami, Y., Yanagida, T. and Fujimoto, Y. (2014) Optical, dosimetric, and scintillation properties of pure sapphire crystals. Jpn. J. Appl. Phys. 53, 02BC12.

63) Masai, H., Yamada, Y., Okumura, S., Yanagida, T., Fujimoto, Y. and Kanemitsu, Y. (2015) Photoluminescence of monovalent indium centres in phosphate glass. Sci. Rep. 5, 13646.

64) Masai, H., Yanagida, T., Fujimoto, Y., Koshimizu, M. and Yoko, T. (2012) Scintillation property of rare earth-free SnO-doped oxide glass. Appl. Phys. Lett. 101, 191906.

65) Kato, T., Okada, G. and Yanagida, T. (2016) Optical, scintillation and dosimeter properties of $\mathrm{MgO}$ transparent ceramic doped with $\mathrm{Mn}^{2+}$. J. Ceram. Soc. Jpn. 124, 559-563.

66) Kato, T., Okada, G. and Yanagida, T. (2016) Optical, scintillation and dosimeter properties of $\mathrm{MgO}$ translucent ceramic doped with $\mathrm{Cr}^{3+}$. Opt. Mater. 54, 134-138.

67) Grabmaier, B.C., Rossner, W. and Berthold, T. (1996) Phosphors in X-ray computed tomography for the $\gamma$-ray Anger camera. In Inorganic Scintillators and Their Application (eds. Dorenbos, P. and van Eijk, C.W.E.). Delft University Press, Netherlands, 29-35.

68) Seferis, I., Michail, C., Valais, I., Zeler, J., Liaparinos, P., Fountos, G. et al. (2014) Light emission efficiency and imaging performance of $\mathrm{Lu}_{2} \mathrm{O}_{3}$ :Eu nanophosphor under X-ray radiography conditions: comparison with $\mathrm{Gd}_{2} \mathrm{O}_{2} \mathrm{~S}: \mathrm{Eu}$. J. Lumin. 151, 229-234.

69) Oya, T., Okada, G. and Yanagida, T. (2016) Scintillation properties of $\mathrm{Lu}_{3} \mathrm{Al}_{5} \mathrm{O}_{12}$ co-doped with Nd and Ce. J. Ceram. Soc. Jpn. 124, 536540.

70) Yanagida, T., Takahashi, H., Ito, T., Kasama, D., Kokubun, M., Makishima, K. et al. (2005) Evaluation of properties of YAG (Ce) ceramic scintillators. IEEE Trans. Nucl. Sci. 52, 18361841.

71) Baryshevsky, V.G., Korzhik, M.V., Moroz, V.I., Pavlenko, V.B., Fyodorov, A.A., Smirnova, S.A. et al. (1991) $\mathrm{YAlO}_{3}$ - Ce-fast-acting scintillators for detection of ionizing-radiation. Nucl. Instrum. Methods Phys. Res. A 58, 291-293.

72) van Loef, E.V.D., Dorenbos, P., Kramer, K. and Gudel, H.U. (2001) Scintillation properties of $\mathrm{LaCl}_{3}: \mathrm{Ce}^{3+}$ crystals: Fast, efficient, and highenergy resolution scintillators. IEEE Trans. Nucl. Sci. 48, 341-345.

73) van Loef, E.V.D., Dorenbos, P., van Eijk, C.W.E., Kramer, K.W. and Gudel, H.U. (2002) Scintillation properties of $\mathrm{LaBr}_{3}: \mathrm{Ce}^{3+}$ crystals: fast, efficient and high-energy-resolution scintillators.
Nucl. Instrum. Methods Phys. Res. A 486, 254258.

74) Combes, C.M., Dorenbos, P., van Eijk, C.W.E., Kramer, K.W. and Gudel, H.U. (1999) Optical and scintillation properties of pure and $\mathrm{Ce}^{3+}$ doped $\mathrm{Cs}_{2} \mathrm{LiYCl}_{6}$ and $\mathrm{Li}_{3} \mathrm{YCl}_{6}: \mathrm{Ce}^{3+}$ crystals. J. Lumin. 82, 299-305.

75) Ogino, H., Yoshikawa, A., Nikl, M., Kamada, K. and Fukuda, T. (2006) Scintillation characteristics of Pr-doped $\mathrm{Lu}_{3} \mathrm{Al}_{5} \mathrm{O}_{12}$ single crystals. J. Cryst. Growth 292, 239-242.

76) Yanagida, T., Kamada, K., Fujimoto, Y., Sugiyama, M., Furuya, Y., Yamaji, A. et al. (2010) Growth and scintillation properties of Pr doped YAP with different $\operatorname{Pr}$ concentrations. Nucl. Instrum. Methods Phys. Res. A 623, 1020-1023.

77) Dorenbos, P., van Eijk, C.W.E., Hollander, R.W. and Schotanus, P. (1990) Scintillation properties of $\mathrm{Nd}^{3+}$ doped $\mathrm{LaF}_{3}$ crystals. IEEE Trans. Nucl. Sci. 37, 119-123.

78) Murray, R.B. (1958) Use of $\mathrm{Li}^{6} \mathrm{I}(\mathrm{Eu})$ as a scintillation detector and spectrometer for fast neutrons. Nucl. Instrum. Methods 2, 237-248.

79) Okada, G., Ueda, J., Tanabe, S., Belev, G., Wysokinski, T., Chapman, D. et al. (2014) Samarium-doped oxyfluoride glass-ceramic as a new fast erasable dosimetric detector material for microbeam radiation cancer therapy applications at the canadian synchrotron. J. Am. Ceram. Soc. 97, 2147-2153.

80) Dixie, L.C., Edgar, A. and Bartle, C.M. (2014) Samarium doped calcium fluoride: a red scintillator and X-ray phosphor. Nucl. Instrum. Methods Phys. Res. A 753, 131-137.

81) Koughia, C., Edgar, A., Varoy, C.R., Okada, G., von Seggern, H., Belev, G. et al. (2011) Samariumdoped fluorochlorozirconate glass-ceramics as redemitting X-ray phosphors. J. Am. Ceram. Soc. 94, $543-550$.

82) Yanagida, T., Fukuda, K., Kawaguchi, N., Kurosawa, S., Fujimoto, Y., Futami, Y. et al. (2011) Scintillation properties of $\mathrm{Nd}^{3+}, \mathrm{Tm}^{3+}$, and $\mathrm{Er}^{3+}$ doped $\mathrm{LuF}_{3}$ scintillators in the vacuum ultra violet region. Nucl. Instrum. Methods Phys. Res. A 659, 258-261.

83) Yanagida, T., Fujimoto, Y., Yagi, H. and Yanagitani, T. (2014) Optical and scintillation properties of transparent ceramic $\mathrm{Yb}: \mathrm{Lu}_{2} \mathrm{O}_{3}$ with different $\mathrm{Yb}$ concentrations. Opt. Mater. 36, $1044-1048$.

84) Fujimoto, Y., Yanagida, T., Yagi, H., Yanagitani, T., Kurosawa, S. and Yoshikawa, A. (2013) Scintillation properties of $\mathrm{Yb}^{3+}$-doped $\mathrm{YAG}$ transparent ceramics. Opt. Mater. 35, 778-781.

85) Fujimoto, Y., Yanagida, T., Kojima, T., Koshimizu, M., Tanaka, H. and Asai, K. (2016) Optical and near-infrared scintillation properties of $\mathrm{Nd}^{3+}$ doped $\mathrm{YVO}_{4}$ crystals. Sens. Mater. 28, 857-861.

86) Moszynski, M., Balcerzyk, M., Kapusta, M. Syntfeld, A., Wolski, D., Pausch, G. et al. (2005) $\mathrm{CdWO}_{4}$ crystal in gamma-ray spectrometry. 
IEEE Trans. Nucl. Sci. 52, 3124-3128.

87) Fritz, S.L. and Cook, L.T. (1987) High-resolution digital x-ray detector utilizing a discrete array of $\mathrm{CdWO}_{4}$ scintillators and a self-scanned photodiode array. Med. Phys. 14, 244-248.

88) Yanagida, T., Watanabe, K., Fujimoto, Y., Uritani, A., Yagi, H. and Yanagitani, T. (2014) Scintillation properties of composite ceramic YAG and its capability on pulse shape discrimination. J. Ceram. Soc. Jpn. 122, 1016-1019.

89) Schönfelder, V., Bennett, K., Bloemen, H., Diehl, R., Hermsen, W. and Lichti, G. (1996) COMPTEL overview: achievements and expectations. Astron. Astrophys. Suppl. Ser. 120, 13-21.

90) Takagi, K. and Fukazawa, T. (1983) Ceriumactivated $\mathrm{Gd}_{2} \mathrm{SiO}_{5}$ single crystal scintillator. Appl. Phys. Lett. 42, 43-45.

91) Kawaharada, M., Hong, S., Murashima, M.M., Kokubun, M., Itoh, T., Makishima, K. et al. (2004) Development and qualification of the HXD-II onboard Astro-E2. Proc. SPIE 5501, 286-295.

92) Yang, K., Melcher, C.L., Koschan, M.A. and Zhuravleva, M. (2011) Effect of Ca co-doping on the luminescence centers in LSO:Ce single crystals. IEEE Trans. Nucl. Sci. 58, 1394-1399.

93) Syntfeld-Kazuch, A., Moszynski, M., Swiderski, L., Szczsniak, T., Nassalski, A., Melcher, C.L. et al. (2008) Energy resolution of calcium co-doped LSO:Ce scintillators. IEEE 2008 Conference record, 2744-2750.

94) Kawamura, S., Kaneko, J.H., Higuchi, M., Yamaguchi, T., Haruna, J., Yagi, Y. et al. (2007) Floating zone growth and scintillation characteristics of cerium-doped gadolinium pyrosilicate single crystals. IEEE Trans. Nucl. Sci. 54, $1383-1386$.

95) Kawamura, S., Kaneko, J.H., Higuchi, M., Fujita, F., Homma, A., Haruna, J. et al. (2007) Investigation of Ce-doped $\mathrm{Gd}_{2} \mathrm{Si}_{2} \mathrm{O}_{7}$ as a scintillator material. Nucl. Instrum. Methods Phys. Res. A 583, 356-359.

96) Suzuki, A., Kurosawa, S., Shishido, T., Pejchal, J., Yokota, Y., Futami, Y. et al. (2012) Fast and high-energy-resolution oxide scintillator: $\mathrm{Ce}-$ doped $(\mathrm{La}, \mathrm{Gd})_{2} \mathrm{Si}_{2} \mathrm{O}_{7}$. Appl. Phys. Express 5, 102601

97) Tsubota, Y., Kaneko, J.H., Higuchi, M., Minagawa, M. and Ishibashi, H. (2014) Crystal growth and scintillation properties of $\mathrm{La}_{0.2} \mathrm{Ce}_{0.05} \mathrm{Gd}_{1.75} \mathrm{Si}_{2} \mathrm{O}_{7}$ (La-GPS) single crystal with triclinic structure. Opt. Mater. 36, 665-669.

98) Koshimizu, M., Yanagida, T., Fujimoto, Y. and Asai, K. (2016) Characterization of luminescence properties of $\mathrm{Gd}_{2} \mathrm{Si}_{2} \mathrm{O}_{7}$ :Ce and $\mathrm{Gd}_{2} \mathrm{Si}_{2} \mathrm{O}_{7}: \mathrm{La}$, Ce under vacuum ultraviolet irradiation. J. Rare Earths 34, 782-785.

99) Pauwels, D., Le Masson, N., Viana, B., KahnHarari, A., van Loef, E.V.D., Dorenbos, P. et al. (2000) A novel inorganic scintillator: $\mathrm{Lu}_{2} \mathrm{Si}_{2-}$ $\mathrm{O}_{7}: \mathrm{Ce}^{3+}$ (LPS). IEEE Trans. Nucl. Sci. 47, $1787-1790$.
100) Yanagida, T., Fujimoto, Y., Ohgi, Y., Yokota, Y., Yoshikawa, A., Kagi, H. et al. (2010) Development and evaluations of apatite crystal scintillators. IEEE Trans. Nucl. Sci. 57, 1308-1311.

101) Igashira, T., Mori, M., Okada, G., Kawaguchi, N. and Yanagida, T. (2017) Photoluminescence and radioluminescence properties of $\left(\mathrm{Gd}_{8} \mathrm{Ca}_{2}\right)$ $\left(\mathrm{SiO}_{4}\right)_{6} \mathrm{O}_{2}$ crystals with different concentrations of Ce. J. Rare Earths 35, 1071-1076. doi: 10.1016/j.jre.2017.02.002.

102) Igashira, T., Mori, M., Okada, G., Kawaguchi, N. and Yanagida, T. (2016) Optical and radiationinduced fluorescence Properties of $\mathrm{Ce}:\left(\mathrm{Gd}_{8} \mathrm{X}_{2}\right)$ $\left(\mathrm{SiO}_{4}\right)_{6} \mathrm{O}_{2}(\mathrm{X}=\mathrm{Mg}, \mathrm{Ca}, \mathrm{Sr}, \mathrm{Ba})$ crystals, Opt. Mater. 64, 239-244.

103) Geusic, E., Marcos, H.M. and van Uitert, L.G. (1964) Laser oscillations in Nd-doped yttrium aluminum, yttrium gallium and gadolinium garnets. Appl. Phys. Lett. 4, 182-184.

104) Zych, E., Brecher, C. and Lingertat, H. (1996) Ceemission from rare earth tantalate hosts. Mater. Sci. Forum 239-241, 257-260.

105) Zych, E., Brecher, C., Wojtowicz, A.J. and Lingertat, H. (1997) Luminescence properties of Ce-activated YAG optical ceramic scintillator materials. J. Lumin. 75, 193-203.

106) Lempicki, A., Randles, M.H., Wisniewski, D., Balcerzyk, M., Brecher, C. and Wojtowicz, A.J. (1995) $\mathrm{LuAlO}_{3}$-Ce and other aluminate scintillators. IEEE Trans. Nucl. Sci. 42, 280-284.

107) Yanagida, T., Ito, T., Takahashi, H., Sato, M., Enoto, T., Kokubun, M. et al. (2007) Improvement of ceramic $\mathrm{YAG}(\mathrm{Ce})$ scintillator to $(\mathrm{YGd})_{3} \mathrm{Al}_{5} \mathrm{O}_{12}(\mathrm{Ce})$ for gamma-ray detectors. Nucl. Instrum. Methods Phys. Res. A 579, 23-26.

108) Yanagida, T., Kamada, K., Fujimoto, Y., Yagi, H. and Yanagitani, T. (2013) Comparative study of ceramic and single crystal Ce:GAGG scintillator. Opt. Mater. 35, 2480-2485.

109) Oya, T., Nakauchi, D., Okada, G., Kawaguchi, N. and Yanagida, T. (2017) Scintillation properties of Ce-doped $\mathrm{Tb}_{3} \mathrm{Al}_{5} \mathrm{O}_{12}$. Nucl. Instrum. Methods Phys. Res. A 866, 134-139.

110) Nakauchi, D., Okada, G., Kawano, N., Kawaguchi, N. and Yanagida, T. (2017) Luminescent and scintillation properties of $\mathrm{Ce}^{3+}: \mathrm{Tb}_{3} \mathrm{Al}_{5} \mathrm{O}_{12}$ crystal grown from Al-rich composition. Appl. Phys. Express 10, 072601.

111) Zorenko, Y., Douissard, P.-A., Martin, T., Riva, F., Gorbenko, V., Zorenko, T. et al. (2017) Scintillating screens based on the LPE grown $\mathrm{Tb}_{3} \mathrm{Al}_{5} \mathrm{O}_{12}$ :Ce single crystalline films. Opt. Mater. 65, 73-81.

112) Nikl, M., Ogino, H., Krasnikov, A., Beitlerova, A., Yoshikawa, A. and Fukuda, T. (2005) Photo- and radioluminescence of $\mathrm{Pr}$-doped $\mathrm{Lu}_{3} \mathrm{Al}_{5} \mathrm{O}_{12}$ single crystal. Phys. Status Solidi A Appl. Res. 202, R4-R6.

113) Dorenbos, P., Visser, R., Vaneijk, C.W.E., Khaidukov, N.M. and Korzhik, M.V. (1993) Scintillation properties of some $\mathrm{Ce}^{3+}$ and $\mathrm{Pr}^{3+}$ doped inorganic crystals. IEEE Trans. Nucl. Sci. 40, 388-394. 
114) Yanagida, T., Fujimoto, Y., Kamada, K., Totsuka, D., Yagi, H., Yanagitani, T. et al. (2012) Scintillation properties of transparent ceramic Pr:LuAG for different $\operatorname{Pr}$ concentration. IEEE Trans. Nucl. Sci. 59, 2146-2151.

115) van Loef, E.V., Wilson, C.M., Cherepy, N.J., Hull, G., Payne, S.A., Choong, W. et al. (2009) Crystal growth and scintillation properties of strontium iodide scintillators. IEEE Trans. Nucl. Sci. 56, 869-872.

116) Hofstadter, R. (1968) Europium-activated Strontium Iodide Scintillators, US patent $3,373,279$, March 12.

117) Burger, A., Rowe, E., Groza, M., Figueroa, K.M., Cherepy, N.J., Beck, P.R. et al. (2015) Cesium hafnium chloride: a high light yield, non-hygroscopic cubic crystal scintillator for gamma spectroscopy. Appl. Phys. Lett. 107, 143505.

118) Saeki, K., Fujimoto, Y., Koshimizu, M., Yanagida, T. and Asai, K. (2016) Comparative study of scintillation properties of $\mathrm{Cs}_{2} \mathrm{HfCl}_{6}$ and $\mathrm{Cs}_{2} \mathrm{ZrCl}_{6}$. Appl. Phys. Express 9, 042602.

119) Sakai, T., Koshimizu, M., Fujimoto, Y., Nakauchi, D., Yanagida, T. and Asai, K. (2017) Luminescence and scintillation properties of $\mathrm{Tl}$ - and In-doped CsCl crystals. Jpn. J. Appl. Phys. 56, 062601.

120) Fujimoto, Y., Saeki, K., Yanagida, T., Koshimizu, M. and Asai, K. (2017) Luminescence and scintillation properties of $\mathrm{TlCdCl}_{3}$ crystal. Radiat. Meas. 106, 151-154. doi: 10.1016/j.radmeas.2017. 03.034 .

121) Saeki, K., Fujimoto, Y., Koshimizu, M., Nakauchi, D., Tanaka, H., Yanagida, T. et al. (2017) Luminescence and scintillation properties of $\mathrm{Tl}$ and Ce-doped $\mathrm{Cs}_{2} \mathrm{HfCl}_{6}$ crystals. Jpn. J. Appl. Phys. 56, 020307.

122) Saeki, K., Wakai, Y., Fujimoto, Y., Koshimizu, M., Yanagida, T. and Asai, K. (2016) Luminescence and scintillation properties of $\mathrm{Rb}_{2} \mathrm{HfCl}_{6}$ crystals. Jpn. J. Appl. Phys. 55, 110311.

123) Fujimoto, Y., Saeki, K., Yahaba, T., Tanaka, H., Yanagida, T., Koshimizu, M. et al. (2016) Photoluminescence and radiation response properties of $\mathrm{Ce}^{3+}$-doped $\mathrm{CsCaCl}_{3}$ crystalline scintillator. Phys. Scr. 91, 094002

124) Fujimoto, Y., Koshimizu, M., Yanagida, T., Okada, G., Saeki, K. and Asai, K. (2016) Thallium magnesium chloride: a high light yield, large effective atomic number, non-hygroscopic crystalline scintillator for X-ray and gamma-ray detection. Jpn. J. Appl. Phys. 55, 090301.

125) Kouzes, R.T., Ely, J.H., Lintereur, A.T., Mace, E.K., Stephens, D.L. and Woodring, M.L. (2011) Neutron detection gamma ray sensitivity criteria. Nucl. Instrum. Methods Phys. Res. A 654, 412416.

126) Runkle, R.C., Bernstein, A. and Vanier, P.E. (2010) Securing special nuclear material: recent advances in neutron detection and their role in nonproliferation. J. Appl. Phys. 108, 111101.

127) Combes, C.M., Dorenbos, P., van Eijk, C.W.E.,
Kramer, K.W. and Gudel, H.U. (1999) Optical and scintillation properties of pure and $\mathrm{Ce}^{3+}{ }_{-}$ doped $\mathrm{Cs}_{2} \mathrm{LiYCl}_{6}$ and $\mathrm{Li}_{3} \mathrm{YCl}_{6}: \mathrm{Ce}^{3+}$ crystals. J. Lumin. 82, 299-305.

128) Glodo, J., Higgins, W.A., van Loef, E.V.D. and Shah, K.S. (2008) Scintillation properties of 1 inch $\mathrm{Cs}_{2} \mathrm{LiYCl}_{6}$ :Ce crystals. IEEE Trans. Nucl. Sci. 55, 1206-1209.

129) Fujimoto, Y., Yanagida, T., Kawaguchi, N., Kurosawa, S., Fukuda, K., Totsuka, D. et al. (2011) Characterizations of $\mathrm{Ce}^{3+}$-Doped $\mathrm{CaB}_{2} \mathrm{O}_{4}$ Crystalline Scintillator. Cryst. Growth Des. 12, 142-146.

130) Toribio, M., García, J.F., Izquierdo-Ridorsa, A., Tauler, R. and Rauret, G. (1995) Simultaneous determination of plutonium alpha emitters by liquid scintillation counting using multivariate calibration. Anal. Chim. Acta 310, 297-305.

131) Yamamoto, S., Iida, T. and Kanno, I. (1997) Development of a high-resolution alpha camera. Nucl. Instrum. Methods Phys. Res. A 392, 291294.

132) Yanagida, T., Fujimoto, Y., Miyamoto, M. and Sekiwa, H. (2014) Optical and scintillation properties of Cd doped $\mathrm{ZnO}$ film. Jpn. J. Appl. Phys. 53, $02 \mathrm{BC} 13$.

133) Yanagida, T., Kawaguchi, N., Fujimoto, Y., Yokota, Y., Miyamoto, M., Sekiwa, H. et al. (2011) Development of $\mathrm{ZnO}$ based radiation monitor for processing facility. Jpn. J. Appl. Phys. 50, 01BG06.

134) Dell'Orto, E., Fasoli, M., Ren, G. and Vedda, A. (2013) Defect-driven radioluminescence sensitization in scintillators: the case of $\mathrm{Lu}_{2} \mathrm{Si}_{2} \mathrm{O}_{7}: \mathrm{Pr}$. J. Phys. Chem. C 117, 20201.

135) Grescovich, C., Cusano, D., Hoffman, D. and Riedner, R.J. (1992) Ceramic scintillators for advanced medical X-ray detection. Am. Ceram. Soc. Bull. 71, 1120-1130.

136) Yanagida, T., Fujimoto, Y. and Watanabe, K. (2014) Dopant concentration dependence on radiation induced positive hysteresis of Ce:GSO and Ce:GSOZ. Radiat. Meas. 61, 16-20.

137) Yanagida, T., Fujimoto, Y., Koshimizu, M., Watanabe, K., Sato, H., Yagi, H. et al. (2014) Positive hysteresis of Ce-doped GAGG scintillator. Opt. Mater. 36, 2016-2019.

138) Fasoli, M., Chiodini, N., Lauria, A., Moretti, F. and Vedda, A. (2007) Effect of deep traps on the optical properties of $\mathrm{Tb}^{3+}$ doped sol-gel silica. Phys. Status Solidi (c) 4, 1056-1059.

139) Moretti, F., Patton, G., Belsky, A., Fasoli, M., Vedda, A., Trevisani, M. et al. (2014) Radioluminescence sensitization in scintillators and phosphors: trap engineering and modeling. J. Phys. Chem. C 118, 9670-9676.

140) Yanagida, T., Watanabe, K., Okada, G., Kawano, N. and Kawaguchi, N. (2017) Optical, scintillation and radiation tolerance properties of Pr-doped pyrosilicate crystals. submitted to J. Phys. Soc. Jpn.

141) Melcher, C.L., Friedrich, S., Spurrier, M.A., 
Szupryczynski, P. and Nutt, R. (2005) Cerium oxidation state in LSO:Ce scintillators. IEEE Trans. Nucl. Sci. 52, 245-248.

142) Watanabe, K., Kawabata, Y., Yamazaki, A., Uritani, A., Iguchi, T., Fukuda, K. et al. (2015) Development of an optical fiber type detector using a Eu:LiCaAlF 6 scintillator for neutron monitoring in boron neutron capture therapy. Nucl. Instrum. Methods Phys. Res. A 802, 1-4.

143) Watanabe, K., Yanagida, T., Fukuda, K., Koike, A., Aoki, T. and Uritani, A. (2015) Portable neutron detector using Ce:LiCaAlF 6 scintillator. Sens. Mater. 27, 269-275.

144) Yanagida, T., Yamaji, A., Kawaguchi, N., Fujimoto, Y., Fukuda, K., Kurosawa, S. et al. (2011) Europium and sodium codoped $\mathrm{LiCaAlF}_{6}$ scintillator for neutron detection. Appl. Phys. Express 4, 106401.

145) Shimamura, K., Baldochi, S.L., Mujilatu, N., Nakano, K., Liu, Z., Sarukura, N. et al. (2000) Growth of Ce-doped $\mathrm{LiCaAlF}_{6}$ and $\mathrm{LiSrAlF}_{6}$ single crystals by the Czochralski technique under $\mathrm{CF}_{4}$ atmosphere. J. Cryst. Growth 211, 302-307.

146) Shuping, L., Xiqi, F., Zhiwei, Z., Nikl, M., Yun, S. and Yubai, P. (2014) Effect of $\mathrm{Mg}^{2+}$ co-doping on the scintillation performance of LuAG:Ce ceramics. Phys. Status Solidi Rapid Res. Lett. 8, 105-109.

147) Kitaura, M., Kamada, K., Kurosawa, S., Azuma, J., Ohnishi, A., Yamaji, A. et al. (2016) Probing shallow electron traps in cerium-doped $\mathrm{Gd}_{3} \mathrm{Al}_{2}$ $\mathrm{Ga}_{3} \mathrm{O}_{12}$ scintillators by UV-induced absorption spectroscopy. Appl. Phys. Express 9, 072602.

148) Yamaji, A., Yanagida, T., Yokota, Y., Kamada, K., Yoshikawa, A. and Pejchal, J. (2012) Quantitive research of the crystallinity of $\mathrm{Pr}$ doped $\mathrm{Lu}_{3}$ $\mathrm{Al}_{5} \mathrm{O}_{12}$. IEEE Trans. Nucl. Sci. 59, 2135-2140.

149) Fujimoto, Y., Yanagida, T., Yagi, H., Yanagitani, T. and Chani, V. (2014) Comparative study of intrinsic luminescence in undoped transparent ceramic and single crystal garnet scintillators. Opt. Mater. 36, 1926-1929.

150) Kubota, S., Suzuki, M., Shiraishi, F. and Takami, Y. (1986) Variation of luminescence decay in $\mathrm{BaF}_{2}$ crystal excited by electrons, alpha particles and fission fragments. Nucl. Instrum. Methods Phys. Res. A 242, 291-294.

151) Kirm, M., Lushchik, A., Lushchik, Ch., Nepomnyashikh, A.I. and Savikhin, F. (2001) Dependence of the efficiency of various emissions on excitation density in $\mathrm{BaF}_{2}$ crystals. Radiat. Meas. 33, 515-519.

152) Yamazaki, A., Watanabe, K., Uritani, A., Iguchi, T., Kawaguchi, N., Yanagida, T. et al. (2011) Neutron-gamma discrimination based on pulse shape discrimination in a Ce: $\mathrm{LiCaAlF}_{6}$ scintillator. Nucl. Instrum. Methods Phys. Res. A 652, $435-438$.

153) Glodo, J., van Loef, E., Hawrami, R., Higgins, W.M., Churilov, A., Shirwadkar, U. et al. (2011) Selected Properties of $\mathrm{Cs}_{2} \mathrm{LiYCl}_{6}, \mathrm{Cs}_{2} \mathrm{LiLaCl}_{6}$, and $\mathrm{Cs}_{2} \mathrm{LiLaYBr}_{6}$ Scintillators. IEEE Trans. Nucl. Sci. 58, 333-338.

154) Yanagida, T., Watanabe, K. and Fujimoto, Y. (2015) Comparative study of neutron and gamma-ray pulse shape discrimination of anthracene, stilbene, and p-terphenyl. Nucl. Instrum. Methods Phys. Res. A 784, 111-114.

155) Yanagida, T., Fujimoto, Y., Watanabe, K., Fukuda, K., Kawaguchi, N., Miyamoto, Y. et al. (2014) Scintillation and optical stimulated luminescence of Ce doped $\mathrm{CaF}_{2}$. Radiat. Meas. 71, 162-165.

156) Yanagida, T. (2016) Ionizing radiation induced emission: scintillation and storage-type luminescence. J. Lumin. 169, 544-548.

(Received Aug. 30, 2017; accepted Oct. 27, 2017)

\section{Profile}

Takayuki Yanagida was born in Japan in 1978. He received a B.S. degree from the Faculty of Science in the University of Tokyo, Japan, in 2002, as well as M.S. and Ph.D. degrees in Physics from the University of Tokyo in 2004 and 2007, respectively. He worked in Tohoku University as a Research Assistant professor from 2007 to 2010, in Institute of Multidisciplinary Research for Advanced Materials, as Associate Professor from 2011 to Aug. 2012, in New Industry Creation Hatchery Center. He also worked in Frontier Research Academy for Young Researchers at Kyushu Institute of Technology, as Associate Professor from Sept. 2012 to Mar. 2015. In 2015, he joined the Graduate School of Materials Science, Nara Institute of Science and Technology as Professor. During his career, he received a total of 17 awards. In 2014, he received the Young

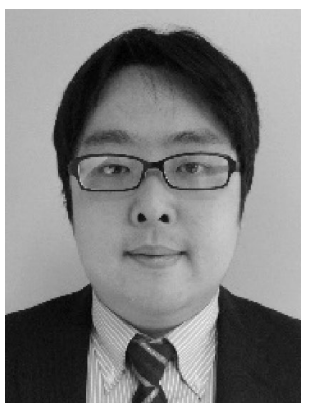
Scientist Award from the Ministry of Education, Culture, Sports, Science and Technology. In 2017, he received the JSPS Prize from the Japan Society for the Promotion of Science.

He is on the Editorial Board of the Journal of Materials Science: Materials in Electronics. His research interests include the synthesis and evaluation of scintillation and dosimeter materials, and to develop radiation detector devices by using these materials. 